\title{
A quantitative study of pitch registers in string quartets opus 17, by Joseph Haydn
}

\author{
Um estudo quantitativo dos registros de alturas nos quartetos de cordas \\ opus 17, de Joseph Haydn
}

\author{
Marcos da Silva Sampaio \\ Vicente Sanches de Oliveira \\ Matheus Travassos \\ Carla Castro \\ Universidade Federal da Bahia
}

\begin{abstract}
In this paper, we present an exploratory study of the pitch registers on the string quartets Opus 17, by Joseph Haydn, according to a quantitative approach. This subject is relevant because the pitch registers studies have revealed noteworthy issues in the Musical Analysis area, the statistical techniques help to detect musical subtleties with a small potential for bias, and because on this corpus, Haydn has established standards for the string quartet genre. The pitch registers study allowed us to identify relevant musical aspects in the repertoire, understand the role of extreme registers in the form segmentation, and observe the prominence of the development and second theme sections, and the feasibility of the quantitative methods. We present a brief theoretical foundation, the methodological framework, the results of the investigation on the quartets' instrument pitches, a discussion about these results, and the conclusions.
\end{abstract}

Keywords: Pitch register; Quantitative analysis; Digital Musicology; String quartet; Joseph Haydn

Resumo: Neste artigo apresentamos um estudo exploratório sobre os registros instrumentais dos quartetos de cordas do opus 17, de Joseph Haydn, segundo uma abordagem quantitativa. $\mathrm{O}$ estudo de registros instrumentais tem revelado questões interessantes na área de Análise Musical, como apoio estrutural; do ponto de vista metodológico, técnicas estatísticas ajudam a detectar sutilezas musicais com um potencial de viés pequeno; e o repertório analisado é importante por ser um dos primeiros a incorporar princípios que se tornaram padrão no gênero de quarteto de cordas em Haydn, como os seis quartetos de quatro movimentos em cada número de opus. A partir deste estudo pudemos identificar pontos musicalmente relevantes do repertório a partir do estudo de registros, compreender o papel dos registros extremos na segmentação formal de peças do repertório, verificar o destaque das seções de desenvolvimento e segundo tema quanto a este aspecto, e a 
A quantitative study of pitch registers in string quartets opus 17, by Joseph Haydn

viabilidade do estudo de registros com métodos quantitativos. Apresentamos uma breve fundamentação teórica, o arcabouço metodológico, os resultados de estudos acerca das alturas dos instrumentos nos quartetos deste opus, uma discussão a respeito destes resultados e as conclusões.

Palavras-chave: Altura musical; Análise quantitative; Musicologia digital; Quarteto de cordas; Joseph Haydn

\section{Introduction}

In this paper, we present an exploratory and quantitative study of the pitch registers of the String quartets opus 17, by Joseph Haydn. The basis of this study is the comparison of numerical values of these registers with the aid of statistical tools, such as detection of atypical values (outliers), correlation and hypothesis tests, contour analysis, and analysis of the musical context. Due to the volume of data, we developed computational tools to assist this study.

Regarding the pitch registers, authors such as Nancy November (2007), William Drabkin (2000), and Ernst Oster (1961) agree with the importance of studying instrumental pitch registers of musical works. November (2007) demonstrated how the register plays a prominent role in Joseph Haydn's four string quartets, James MacKay (2013) showed the Haydn's ability to use extreme registers to assist formal articulation in works for classic five-octaves keyboards, and Charles Rosen (2001, p. 210) highlighted the extreme registers usage to create climax in the music of Haydn, Mozart, and Beethoven. The literature about registers generally emphasizes the formal structure and more descriptive terminology, without quantitative approaches.

Concerning the methodology used, Jan Beran (2004, p. vii) predicted the role of statistics in the development of the area of musicology due to the focus of statistics in the search for structures in data, due to the mathematical nature of its methods-applicable to several data types-, and for its ability to extract essential information from music. Statistical techniques help to detect musical subtleties with less chance of bias. Quantitative methods and computational support are the basis for several studies in the area of Digital Musicology.

Regarding the studied repertoire, the string quartets opus 17 by Joseph Haydn, together with opus 9 and 20, are considered central to the development of this genre in the 18th century (Birson 2015, p. 4 and 5). Haydn is an exceptional composer, especially for Viennese classicism (Antonicek et al. 2001), he stood out 
MUSICA THEORICA Revista da Associação Brasileira de Teoria e Análise Musical 2020,

v. 5, n. 1, p. 119-177 - Journal of the Brazilian Society for Music

in the development of the String Quartet genre and influenced great composers of his time.

\section{Theoretical foundation}

In this study, we have conducted a brief literature review about the instrumental pitch register analysis, Digital Musicology, Statistics, repertoire, and music contours.

\subsection{Instrumental pitch registers}

The literature has several studies on instrumental pitch registers under different approaches. Most of these studies take place in the Schenkerian analysis context related to the use of registers to design the form on a large scale.

Ernst Oster (1961) showed the significant role that the register plays in creating connections in the composition. He presented situations in which the register contributes in an essential way to the establishment of structural, thematic-motivic, or contrapuntal relationships, with examples of works by Mozart, Bach, Schubert, Beethoven, Brahms, and Mendelssohn. He concluded by stating that the register is important as one of the structural elements of music, which should not be neglected in composition or analysis.

James MacKay (2013) studied the role of register extremes in Haydn's piano works. He investigated how the composer incorporated the extreme registers of the keyboard (harpsichord, piano, and clavichord) in his total largescale planning. He studied how he highlighted formal junctions, relevant events on the phrase level, cadences and modulations, and drew attention to unusual or musically expressive harmonies.

James Webster (1977) studied the role of bass in the Haydn's string quartets. He presented historical questions about the ensemble, tessitura, crossings, and characteristics of using the violoncello. Regarding opus 17, he concluded that Haydn's writing is accurate, with a soloist violoncello on the bass part.

Nancy November (2007) carried out a case study in four Haydn string quartets, seeking to demonstrate how the register, in interaction with other compositional parameters, in particular harmony, motive structure, texture, and dynamics, can play a significant role in the modeling of form. She presented a brief study review of the register and made a reflection on the reasons for the 
A quantitative study of pitch registers in string quartets opus 17 , by Joseph Haydn

marginalization of the register study. She highlighted the Heinrich Schenker pioneering spirit in the attempt to define the register in terms of its musical significance. She concluded that, in the analyzed works, the register has an outstanding compositional role, together with harmony, rhythm, and motivic treatment. Finally, she recommended future studies of the register in a larger corpus of early quartets, including Mozart's.

William Drabkin (2000, p. 35-38), addressed the role of registers in the violoncello voice in Haydn's early string quartets and detailed the structural aspects surrounding the instrumental registers of this instrument in the quartet op. 9, n. 5, mov. 3, demonstrating the impact on the register of the other instruments. About the first quartets, he also highlighted the use of the register limited to the low $\mathrm{F}$ and considered the exceptional use of the low $\mathrm{C}$ in the slow movement of the quartet op. 2, n. 4, as evidence of the effectiveness of the violoncello in the low register, compared to the double bass. According to November (2007, p. 289), Drabkin's text is one of the rare ones present in the literature about the use of register by Haydn.

Olli Väisälä (2009) studied J. S. Bach's two-voice inventions from a Schenkerian perspective. He emphasized three aspects: a) figuration and register as compositional determinants, b) the expansion of characteristic surface figures, and c) the meaning of Ursatz for real musical events. He presented examples of different ways in which figuration and registration relate to the structure and how they function as structural determinants.

Malcolm Miller (2006) demonstrated how Beethoven used the register structure in the context of Opus 59 quartets to reinforce the use of the sonata principle, within and between movements, and unify each work by promoting a cycle of coherence in the op. 59 as a whole. Miller presented a brief review of the literature on the study of register and sought to analyze these works in an intermediate point between the focus on the musical surface and the Schenkerian hierarchical approaches. The author exemplified the reinforcement of the principle of Sonata Form with the movement for a higher-pitch register in the second theme, in comparison to the first theme and transition.

Lewis Lockwood (1992) addressed the expansion of large-scale registers in string quartets in conjunction with the thematic and harmonic strategy in quartets op. 59, by Beethoven, and Jonathan Bernard (1981) analyzed Edgard 
Varèse's work from the perspective of registers, concluding that pitch and register are important structural determinants in the French composer's music.

There is, therefore, a reasonable number of studies on registers in the literature, with an emphasis on formal structure and with more descriptive terminology, without quantitative approaches.

\subsection{Digital Musicology}

The study of musical structures based on quantitative methods is not new neither as a tool for exploring repertoires, nor for investigating theoretical models. For example, David Huron used such methods to investigate the arch contour hypothesis in popular songs (1996) and, in co-authorship with Mathew Royal, to verify eight theoretical models for melodic accents (1996). A not so recent trend is the use of such methods for studying style. For example, Peter van Kranenburg and Eric Baker (2004) conducted style studies on works from the Baroque and Classical periods, and Héctor Bellman (2011) addressed the categorization of styles.

Due to the large existing volume of data, the computer has been assisting the statistical analyzes of musical repertoires. Authors such as Anja Volk, Franz Watt, and Peter van Kranenburg (2011), Alan Marsden (2015), and Peter Schubert and Julie Cumming (2015) defend the investigation of musicological issues with computational approaches. Volk and co-authors argue that such approaches generate new perspectives for old problems. Marsden adds as an objective of computer-aided analysis, the rapid response to complex analytical musical questions, and the testing of hypotheses without bias of human interaction. Schubert and Cumming highlight the possibility of transforming style study into a matter of verifying quantifiable characteristics.

\subsection{Statistics}

According to Jan Beran (2004), descriptive and exploratory statistical analysis is especially interesting in music because they can identify musical relevant aspects hard to detect due its subtle nature. These methods include center, variation, and distribution studies, identification of outliers, and data visualization. In this study, we have used boxplot charts for data visualization, linear correlation, detection of outliers, hypothesis tests, and normality tests. All 
A quantitative study of pitch registers in string quartets opus 17, by Joseph Haydn

of these methods are available in most Basic Statistics books, such as the one by Mario Triola (2013).

The boxplot chart is useful for a preliminary description of the variable data distribution. In this study, we used this tool to visualize, for example, how the viola pitches are distributed in all movements (see Fig. 1). This type of boxplot also identifies outliers (the circles in these distributions), as it occurs in the movement op17n2-01, ${ }^{1}$ for instance.

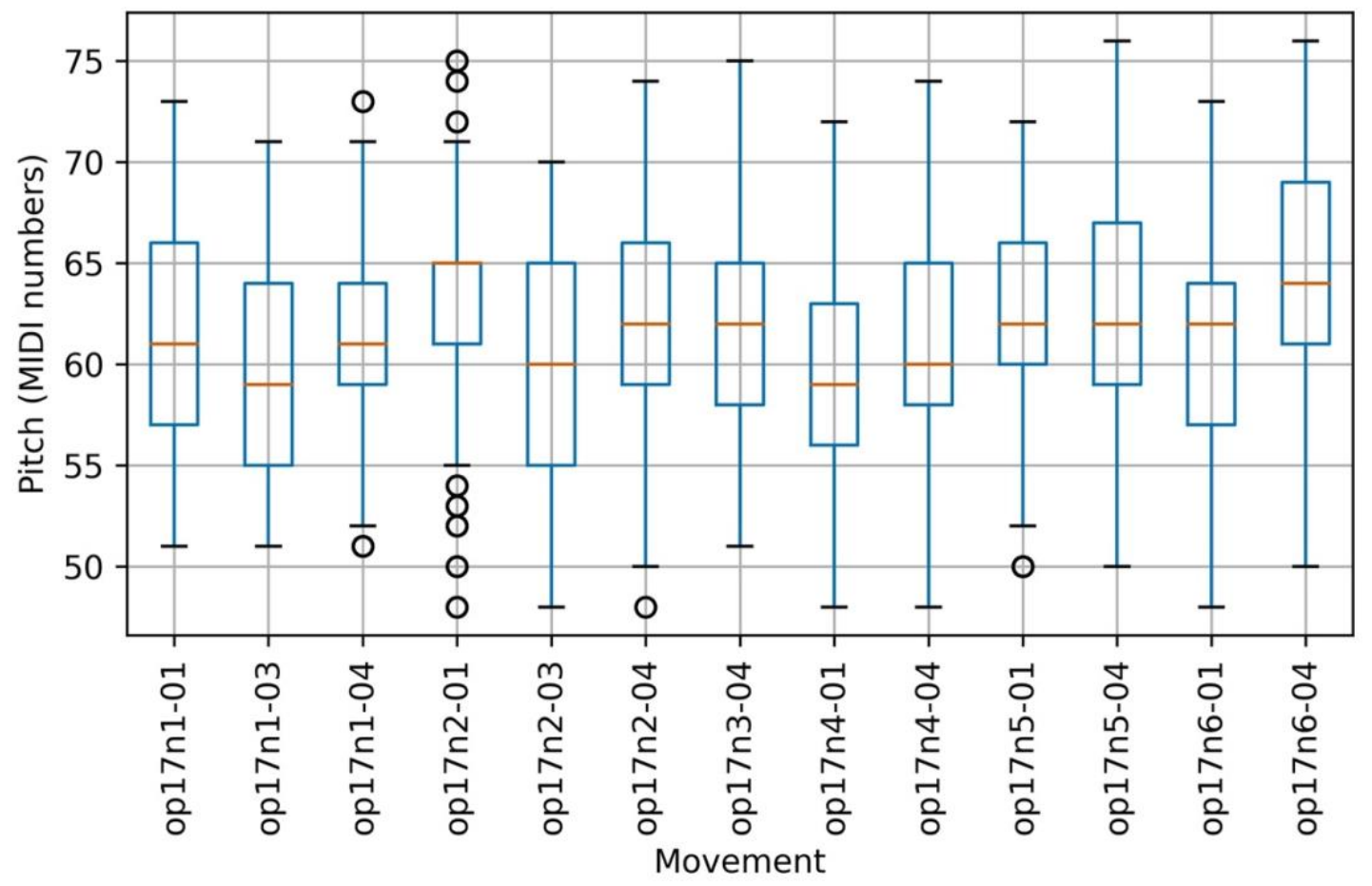

Figure 1: Distribution of the viola pitch values in all the analyzed movements. In the MIDI standards for pitch representation, 60 value means C4 pitch. Source: authors

The outlier identification allows detecting extreme values in distributions. In this study, it was useful to check, for example, extremes in the pitch notes. For instance, the distribution of the viola pitches in the op17n2-01 movement (see boxplot in Fig. 1) is detailed in the histogram in Fig. 2. There is a high concentration of values between 60 and about 70 semitones and some values distant from this concentration, below 55 and above 71 semitones. These distant

\footnotetext{
${ }^{1}$ In this article, we have used codes like op17n2-01 to identify the movements. The "n2" refers to the second quartet of opus 17 and " 01 " is the first movement of this quartet. The codes like E.T1 and E.T2 identify the exposition's first and second themes. For more information, see section 3.1.
} 
MUSICA THEORICA Revista da Associação Brasileira de Teoria e Análise Musical 2020,

values are pitches little used in the movement and deserve a special study of their context. We used this technique to select these points for studying the musical context.

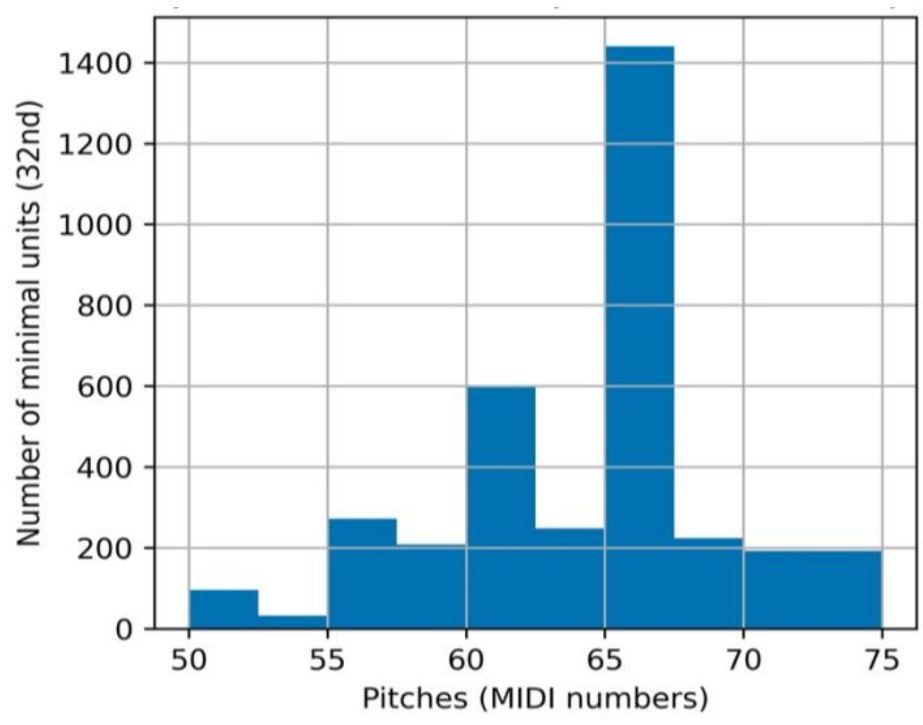

Figure 2: Non-normal distribution of the viola pitches in the development section of the movement op17n2-01. Source: authors

Linear correlation is useful for identifying relationships between two variables. In this study, we have used this technique to verify, for example, the positive correlation between first and second violin pitches.

Hypothesis tests allow verifying the properties of a population. These tests were useful to check multiple questions, such as "in the exposure of the movement op17n1-01, are the values of the first violin pitches of the first theme lower than those of the second theme?". An observation in Fig. 3 indicates this property, but it is not always possible to perceive it so clearly. 
A quantitative study of pitch registers in string quartets opus 17, by Joseph Haydn

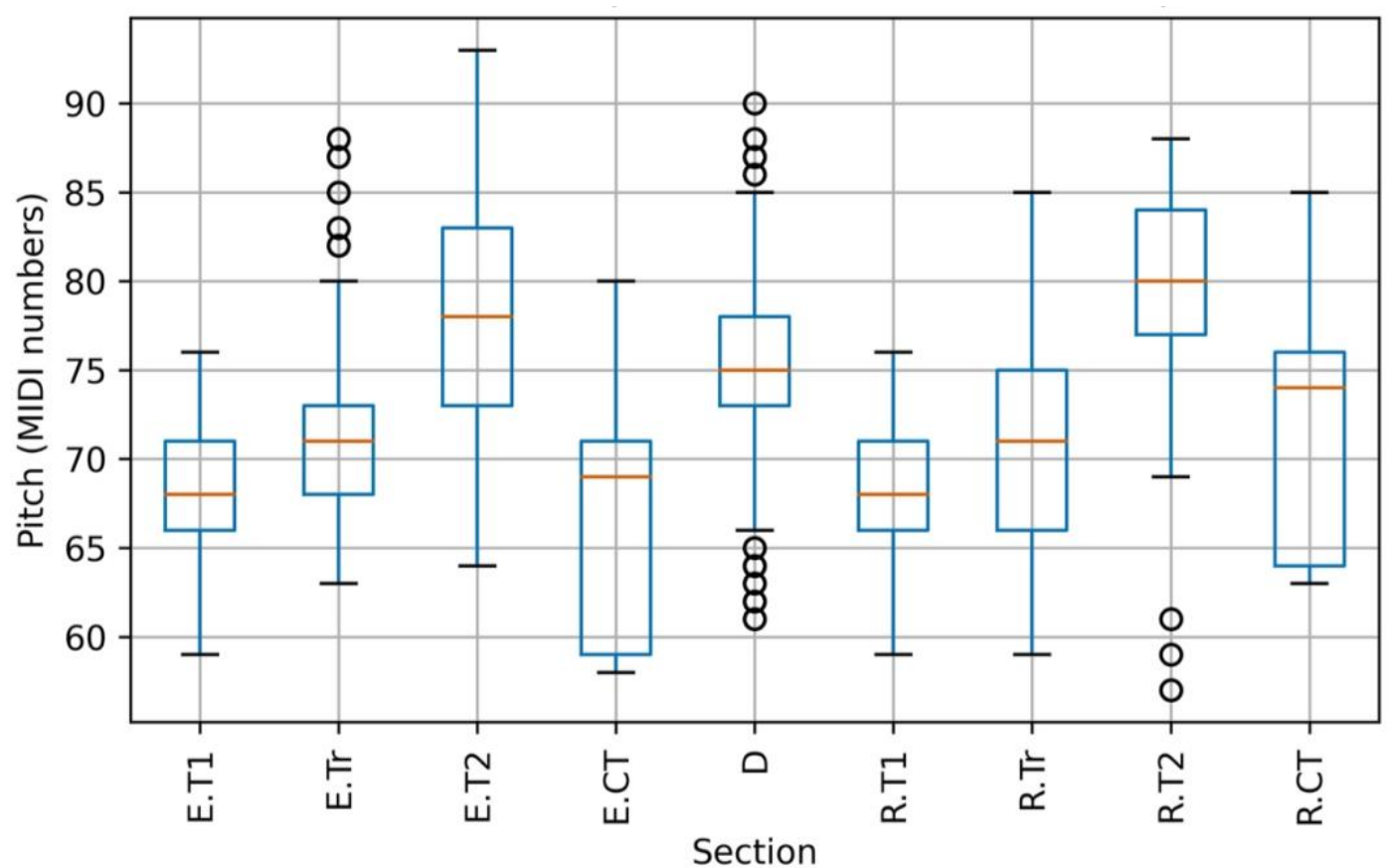

Figure 3: Distribution of the first violin pitches in the movement op17n1-01. Source: authors

Finally, the normality test allows us to check whether the distribution of the values in a collection has a normal probability distribution. This test is useful to guide the choice of statistical study methods: parametric in the case of normal distributions, and non-parametric in non-normal distributions. Although nonparametric methods are less robust than parametric methods, they are more suitable for non-normal distributions and can have high efficiency with larger samples (Triola 2013, p. 676).

\subsection{Haydn's Opus 17}

Haydn's opus 17 string quartet ensemble is relevant mainly for the importance of its composer and genre. Joseph Haydn was one of the most important composers in the history of music, he wrote numerous works for diverse instrumental formations, and had a prominent role in the development of the Sonata Form, the Symphony, and the String Quartet. The latter genre is central to his chamber music and, although he was not its creator, ${ }^{2}$ he is considered his father (Webster; Feder 2001). Between the years 1755 and 1803,

\footnotetext{
${ }^{2}$ According to Floyd and Margaret Grave (2006), composers like Franz Xaver Richter (1709-1789) and Ignaz Holzbauer (1711-1783) preceded Haydn in publishing works with this background.
} 
MUSICA THEORICA Revista da Associação Brasileira de Teoria e Análise Musical 2020, v. 5, n. 1, p. 119-177 - Journal of the Brazilian Society for Music

Haydn wrote 68 works for the string quartet ensemble, divided into 17 opuses $^{3}$ (Webster 1975). Besides, Haydn influenced important composers such as Wolfgang Amadeus Mozart and Ludwig van Beethoven (Rosen 1997; Rumph 2014; Birson 2015).

Opus 17 is made up of six quartets with four movements, composed in 1771. From the moment he composed opus 9, 17, and 20, Haydn adopted the format of six quartets of four movements, which would become standard for his quartets and of many of his contemporaries. Birson (2015) highlights the impact of opus 17, in particular, on the work of other composers when he stated that "If these quartets [op. 17] did not provide direct models for the music of these later composers, they at least proved to be lessons in composition" for Mozart, Beethoven, and Schubert, among others (Ibid, p. 5).

Unlike another opus such as 33, there is a lack of studies on the quartets of opus 17. Floyd and Margaret Grave (2006) made a brief historical and stylistic review of all quartets by Haydn, and W. Dean Sutcliffe (1992) analyzed general musical characteristics and compositional choices of opus 17, especially the movements of minuets and finales.

From a thematic and textural point of view, Nancy November (2008) discussed the structuring of "aria" solo in this opus, especially in slow movements, and Dénes Bartha (1969) addressed the thematic character of Haydn's string quartet Finale, a brief description of each quartet, including opus 17.

In the harmonic, rhythmic and formal terms, Adem Birson (2014 and 2015) addressed chromatic harmony in the opus 9 and 17 quartets, emphasizing its use in the op. 17 n. 2 and op. 17 n. 6 quartets; Jack Adrian (1991) explored the use of "apparent tonic" in the development sections of several works in Sonata Form and described the occurrence of the phenomenon in Haydn's op. 17 n. 2, among other works; Steve Larson (2003) demonstrated in the quartet op. 17 n. 4 procedures of false recapitulation and "anticipated surprise" in his study of recapitulation sections in the first movements of Haydn quartets; James MacKay (2014) examined formal procedures in movements of this opus; Floyd Grave (1995) discussed the displacement of hemiola in the minuet of op. 17 n. 5 in his study of metric dissonance in several works by Haydn.

\footnotetext{
${ }^{3}$ Opus 0, 1, 2, 9, 17, 20, 33, 42, 50, 54, 55, 64, 71, 74, 76, 77 e 103.
} 
A quantitative study of pitch registers in string quartets opus 17, by Joseph Haydn

\subsection{Musical Contour}

Music contour is a generalization of the concept of melodic contour, has its study supported by a theory of mathematical bases developed by several authors, and can help to understand the behavior of orderable musical parameters. According to Robert Morris (1987, p. 283), "a contour is a set of points in one sequential dimension ordered by any other sequential dimension". These points are listed with positive integer values, preserving the order of the parameter. For example, the melodic contour of the initial motif of the first movement of quartet n. 1 of Haydn's opus 17 (Ex. 1) could be represented as $<02$ $4310>$.

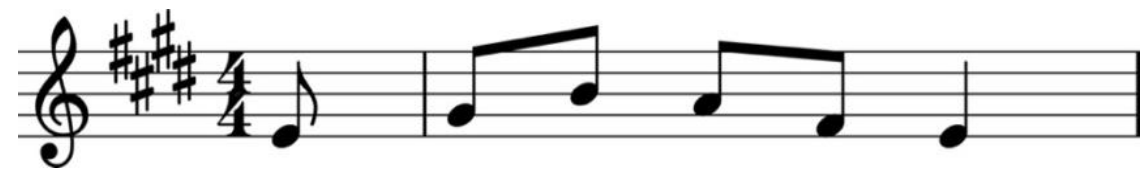

Example 1: Initial motive of the first movement of quartet n.1 of Haydn's opus 17.

Source: authors

This theory has operations that allow comparing musical structures from the abstraction of their contours, finding common prime values, calculating their similarity, and verifying the tendency of upward or downward direction. In this study, we used three features of this theory: class-equivalent contours, developed by Elizabeth Marvin (1987), contour reduction, developed by Robert Morris (1993) and refined by Rob Schultz (2009) and Marcos Sampaio (2016), and the contour similarity algorithm, developed by Mark Schmuckler (2010).

A class of equivalent contours comprises all contours in which the relations between internal points are equivalent, including the contours related by reflection operations, such as inversion and retrogradation. Each class has a prime form as its representative. It is an analogy to the concepts of interval-class vector, set classes, and prime form of the Post-Tonal Theory. Equivalence is useful for identifying similar contours.

The contour reduction operation consists of eliminating intermediate points until reaching the most compact version of the contour possible. The reduced version contains the most important points of the original contour. Thus, contours, reducible to a common one, have their most important points in common. These contours are called primes. 
Contour similarity is an operation that informs, in real values from 0 to 1 , how much two contours are similar to each other. There are several algorithms for this purpose, especially those of Schmuckler and Sampaio (2018), which are the only ones capable of processing contours as large as those proposed in this work (see discussion on Sampaio 2018). The similarity is a less rigid way of observing relationships between contours than operations of reflection. It is possible to perceive more subtle levels of similarity with this tool.

\section{Methodology}

In this study, we have followed an exploratory orientation and used two methodological approaches, one quantitative and the other qualitative. We have employed quantitative statistical techniques for distribution visualizing, detecting outliers, hypothesis tests, and correlation studies. For the qualitative nature, we have performed an analysis of the musical context of the fragments highlighted by the quantitative studies.

The exploratory approach guided the formulation of the hypothesis tests. Instead of starting from hypotheses with values for a previously defined test, such as "the highest pitch in the violoncello voice is a G4", we have tested all the hypotheses of the type "the pitches of the first violin in the second theme section are higher than those in the transition section". Thus, we were able to verify the tests results and seek explanations in the qualitative stage.

\subsection{Scope and characterization of the corpus}

James MacKay (2014) has identified 17 Sonata Form movements in this opus, including four unusual sonata type movements ${ }^{4}$ (n3-03, n4-03, n5-03, and n6-03). We have restricted our study scope to the 13 Sonata Form movements that include Exposition, Development, and Recapitulation, with subdivision of the exposition and recapitulation in first and second themes, transition, and conclusive (or closing) theme. We have opted for these movements because the Sonata Form is the most numerous formal organization in the opus and because this form type favors the data comparison by section types (for example, the exposition's first and second theme). We have considered the codetta section to be part of the concluding theme section, so we chose not to identify them.

\footnotetext{
${ }^{4}$ For more information on special types of Sonata Form, see Hepokoski and Warren (2006).
} 
A quantitative study of pitch registers in string quartets opus 17, by Joseph Haydn

In this text, we have shortened the names of the Sonata Form sections with the letters E, D, R, and C for Exposition, Development, Recapitulation, and Coda and $\mathrm{T} 1, \mathrm{Tr}, \mathrm{T} 2$, and $\mathrm{CT}$ for the first theme, transition, second theme, and concluding theme. Thus, R.T1 represents the first theme in the recapitulation, for example. Table 1 contains our formal analysis, with the numbers of the initial measure of each section.

\begin{tabular}{lrrrrrrrrrr} 
& E.T1 & E.Tr & E.T2 & E.CT & D & R.T1 & R.Tr & R.T2 & R.CT & C \\
\hline op17n1-01 & $1^{*}$ & $7^{*}$ & 25 & 41 & $44^{*}$ & $76^{*}$ & $82^{*}$ & 92 & 108 & - \\
op17n1-03 & 1 & 17 & 29 & $39^{*}$ & 41 & 53 & - & 62 & $74^{*}$ & - \\
op17n1-04 & $1^{*}$ & $13^{*}$ & $35^{*}$ & $74^{*}$ & $85^{*}$ & $156^{*}$ & - & 168 & $207^{*}$ & $216^{*}$ \\
op17n2-01 & 1 & 5 & 12 & 36 & 39 & 71 & 75 & 82 & 98 & - \\
op17n2-03 & 1 & 13 & 23 & 35 & 41 & 53 & - & 69 & 81 & 87 \\
op17n2-04 & $1^{*}$ & $13^{*}$ & $40^{*}$ & 73 & $80^{*}$ & $98^{*}$ & - & $131^{*}$ & 164 & - \\
op17n3-04 & $1^{*}$ & $5^{*}$ & $10^{*}$ & 18 & $27^{*}$ & $42^{*}$ & - & $53^{*}$ & 61 & - \\
op17n4-01 & 1 & 9 & 20 & 43 & 54 & 92 & - & 102 & 110 & - \\
op17n4-04 & 1 & 13 & 27 & 40 & 50 & 81 & - & 95 & 108 & 120 \\
op17n5-01 & $1^{*}$ & $9^{*}$ & 13 & $26^{*}$ & $34^{*}$ & $69^{*}$ & - & 73 & $82^{*}$ & - \\
op17n5-04 & $1^{*}$ & $20^{*}$ & $30^{*}$ & $52^{*}$ & $63^{*}$ & $94^{*}$ & - & $106^{*}$ & $122^{*}$ & - \\
op17n6-01 & $1^{*}$ & $15^{*}$ & 30 & $57^{*}$ & $74^{*}$ & $117^{*}$ & $140^{*}$ & 157 & $184^{*}$ & - \\
op17n6-04 & $1^{*}$ & 34 & 45 & 58 & $63^{*}$ & $91^{*}$ & 117 & 128 & 141 & - \\
\hline
\end{tabular}

Table 1: Identification of measure numbers at the beginning of the sections in each movement. The asterisk indicates the upbeat sections. Source: authors

This corpus contains three monothematic movements and four movements with false recapitulation (see Table 2).

\begin{tabular}{lll}
\hline & Monothematic & False Recapitulation (measure) \\
Movement & & \\
\hline op17n1-01 & False & 63 \\
op17n1-03 & True & - \\
op17n1-04 & True & 85 \\
op17n2-01 & False & - \\
op17n2-03 & False & - \\
op17n2-04 & False & - \\
op17n3-04 & True & - \\
op17n4-01 & False & 86 \\
op17n4-04 & False & 78 \\
op17n5-01 & False & - \\
op17n5-04 & False & - \\
op17n6-01 & False & - \\
op17n6-04 & False & - \\
\hline
\end{tabular}

Table 2: Identification of movements with monothematic sonata and the presence and location of false recapitulations. Source: authors 
MUSICA THEORICA Revista da Associação Brasileira de Teoria e Análise Musical 2020,

v. 5, n. 1, p. 119-177 - Journal of the Brazilian Society for Music

\subsection{Data preparation}

We have used two data types: the pitch notes of each instrument and the harmonic interval between the extreme pitches at each point in time. We have called this interval the vertical sonority's amplitude and represented the pitches and amplitudes in integer values sequences based on the MIDI standard for the note pitches.

We have converted this data from digital scores in Kern format available at the Center for Computer Assisted Research in the Humanities (CCARH) repository. ${ }^{5}$ We added the scores for movements 1 and 4 of quartet $n$. 4 , absent in this repository, and we fixed errors in rhythmic notation and pitch. We used the Dover edition (Haydn 2000) as a basis for including the missing movements and correcting the identified errors.

We developed algorithms to extract the pitch values based on the Humdrum $^{6}$ and Music $21^{7}$ toolsets. In the extraction, we used a minimum time lapse, equivalent to a 32 nd note, to maintain the proportionality of each pitch in terms of duration. In this way, we represented a C4 quarter note, for example, with a sequence with 32 units of 60 values (MIDI number equivalent to the interval from $\mathrm{C}_{0}$, in semitones). In the total of the quartets, the use of minimum lapse in coding generated 823,320 minimum units and a sum of 4,116,600 values of pitches and sonorities' amplitude. ${ }^{8}$

In the case of double, triple, or quadruple stops, we encoded the average of the values of the chord pitches. For example, in a chord with the notes G4 and E5 (67 and 76 semitones from $\mathrm{C}_{0}$ ), we encoded the mean, 71.5 semitones. Throughout this study, especially in correlation studies, this choice proved to be more reasonable than choosing the highest or lowest grade. The correlation between the different properties' values (viola and violoncello pitches, for example) requires matching these values. Thus, we had to choose to a) remove all the chords from the study, b) choose the chord highest or lowest pitch, or c) choose a value to represent the chord pitches. We opted for the third option.

This study required a large number of data comparisons. Due to this great volume of information, we have created the section-object's data structure and a

\footnotetext{
${ }^{5}$ Available at http://kern.ccarh.org/.

${ }^{6}$ Available at https://www.humdrum.org/.

${ }^{7}$ Available at https://web.mit.edu/music21/.

${ }^{8}$ All these data are available at https://github.com/msampaio/music-research-data/.
} 
A quantitative study of pitch registers in string quartets opus 17, by Joseph Haydn

series of comparison strategies. The section-object is a structural class that contains information about a formal section of a corpus movement. Each sectionobject contains the following attributes:

- Movement identification

- Section identification

- First violin pitch values sequence

- Second violin pitch values sequence

- Viola pitch values sequence

- violoncello pitch values sequence

- Vertical sonorities' amplitude values sequence

We, therefore, created 111 section-objects, one for each section of each corpus movement, as seen in Table 3. The section-object's data comparisons can occur in three modalities: one to one (1-1), one to several (1-n), and several to several (n-n). For instance, between E.T1 and E.T2 sections of a given movement (case 1-1), between E.T1 section and the others of a given movement (case 1-n), or among all E.T1 sections (case n-n).

\begin{tabular}{l|llllllllll} 
Movement & E.T1 & E.Tr & E.T2 & E.CT & D & R.T1 & R.Tr & R.T2 & R.CT & C \\
\hline op17n1-01 & obj & obj & obj & obj & obj & obj & obj & obj & obj & \\
op17n1-03 & obj & obj & obj & obj & obj & obj & & obj & obj & \\
op17n1-04 & obj & obj & obj & obj & obj & obj & & obj & obj & obj \\
op17n2-01 & obj & obj & obj & obj & obj & obj & obj & obj & obj & \\
op17n2-03 & obj & obj & obj & obj & obj & obj & & obj & obj & obj \\
op17n2-04 & obj & obj & obj & obj & obj & obj & & obj & obj & \\
op17n3-04 & obj & obj & obj & obj & obj & obj & & obj & obj & \\
op17n4-01 & obj & obj & obj & obj & obj & obj & & obj & obj & \\
op17n4-04 & obj & obj & obj & obj & obj & obj & & obj & obj & obj \\
op17n5-01 & obj & obj & obj & obj & obj & obj & & obj & obj & \\
op17n5-04 & obj & obj & obj & obj & obj & obj & & obj & obj & \\
op17n6-01 & obj & obj & obj & obj & obj & obj & obj & obj & obj & \\
op17n6-04 & obj & obj & obj & obj & obj & obj & obj & obj & obj &
\end{tabular}

Table 3: Matrix of section-objects. Source: authors

In the one-to-many case, we have made comparisons among sectionobjects from the same movement or of the same section type, like among the o17n4-04 E.T2 section-object's data (red cell in Table 4) and the other movements' E.T2 section's data (blue column in Table 4). In this case, we used the Set Theory's Complement concept to refer to these other section-objects. The complement concept can be related to the other section types objects and the other corpus' section-objects. 
MUSICA THEORICA Revista da Associação Brasileira de Teoria e Análise Musical 2020, v. 5, n. 1, p. 119-177 - Journal of the Brazilian Society for Music Theory and Analysis @ TeMA 2020 - ISSN 2525-5541

\begin{tabular}{l|llllllllll} 
Movement & E.T1 & E.Tr & E.T2 & E.CT & D & R.T1 & R.Tr & R.T2 & R.CT & C \\
\hline op17n1-01 & obj & obj & obj & obj & obj & obj & obj & obj & obj & \\
op17n1-03 & obj & obj & obj & obj & obj & obj & & obj & obj & \\
op17n1-04 & obj & obj & obj & obj & obj & obj & & obj & obj & obj \\
op17n2-01 & obj & obj & obj & obj & obj & obj & obj & obj & obj & \\
op17n2-03 & obj & obj & obj & obj & obj & obj & & obj & obj & obj \\
op17n2-04 & obj & obj & obj & obj & obj & obj & & obj & obj & \\
op17n3-04 & obj & obj & obj & obj & obj & obj & & obj & obj & \\
op17n4-01 & obj & obj & obj & obj & obj & obj & & obj & obj & \\
op17n4-04 & obj & obj & obj & obj & obj & obj & & obj & obj & obj \\
op17n5-01 & obj & obj & obj & obj & obj & obj & & obj & obj & \\
op17n5-04 & obj & obj & obj & obj & obj & obj & & obj & obj & \\
op17n6-01 & obj & obj & obj & obj & obj & obj & obj & obj & obj & \\
op17n6-04 & obj & obj & obj & obj & obj & obj & obj & obj & obj &
\end{tabular}

Table 4: Selection of the "first theme" section-object of the op17n4-04 movement (in red) and its complement concerning the section type (in blue). Source: authors

In some situations, the comparison demanded gathering data from multiple section-objects. For example, the question "Are the values of the violoncello pitches higher in the E.T2 section than in others?" depends on two values sets: violoncello pitches of the E.T2 section and of all the other sections. In this second set, all the sections' data are joined. We gathered the data and proceeded with the statistical test (see section 3.3).

So, there are three possible comparison types:

Comparison between different attributes of the same section-object. For example, given any section-object, the comparison between the first violin pitch values and the sonorities' amplitude of this object.

Comparison of the same attribute type between a section-objects pair (11). For example, violoncello pitch values between the op17n1-01-E.T1 and op17n1-01-R.T1 section-objects.

Comparison of a section-object's attribute type with its complement (1-n or $n-n)$.

\subsection{Definition of statistical tools}

Initially, we made comparative studies of value distributions with the support of Boxplot graphs with multiple musicological crossings. For instance, we made comparative charts with vertical sonorities' amplitudes values (Fig. 4) and with violoncello pitches values in Development sections of all movements (Fig. 5). 
A quantitative study of pitch registers in string quartets opus 17 , by Joseph Haydn

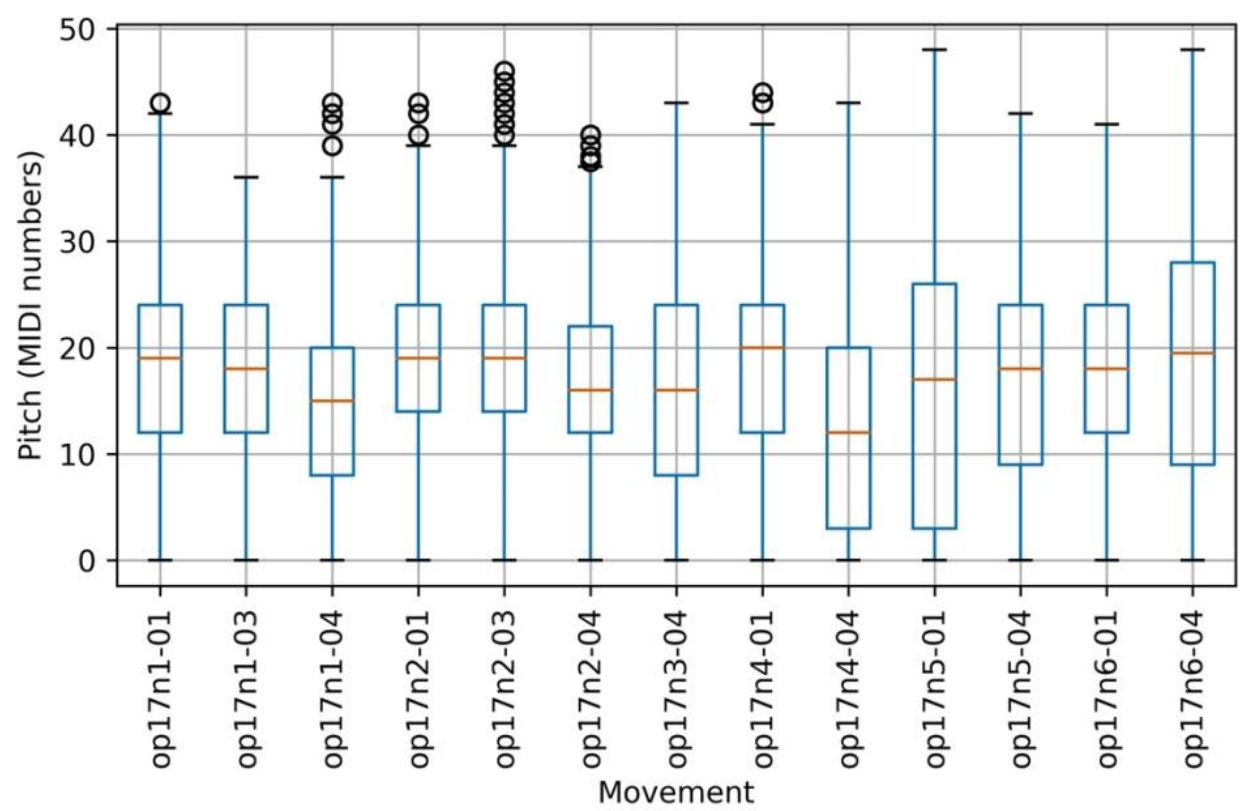

Figure 4: Distribution of the movements' vertical sonorities' amplitude values. Source: authors

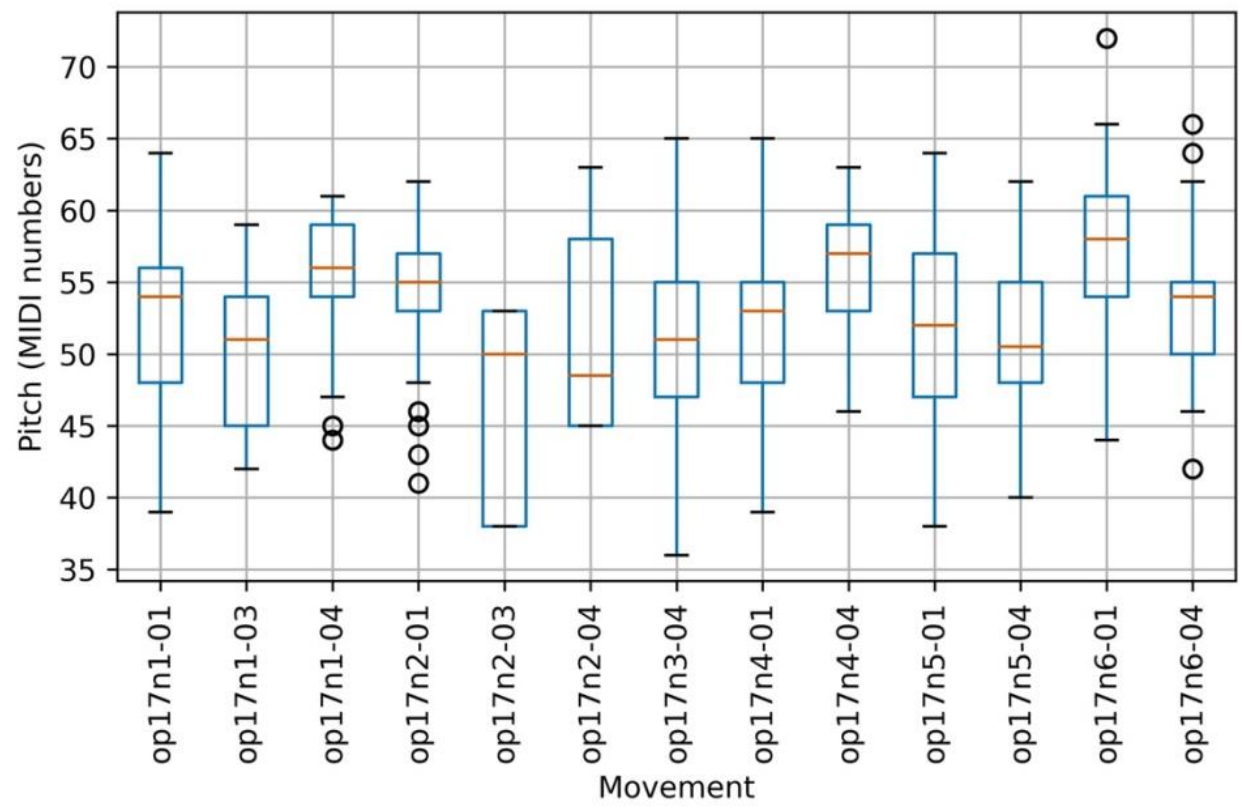

Figure 5: Distribution of the violoncello's pitch values in the movements. Source: authors

We used nonparametric tests because $95.7 \%$ of the data for each attribute of the section-objects show evidence of non-normality, according to the D'Agostino and Pearson test (see section 2.3). Thus, we used the Wilcoxon 
method for the studies of the correlation between values, the interquartile difference for the outliers detection, and the Mann and Whitney method for checking hypotheses of higher and lower values. In all tests performed, we used a significance level of $1 \%$.

We carried out studies of linear correlation between different attributes of the same movement or section, like the correlation between the first violin's and the violoncello's pitches.

We also carried out two types of study of outliers: data for each movement and data for each section. In addition to calculating these values, we made their location in the compositions. We identified 148 positions with outliers in the study by movement, and 651 in the investigation by section. We performed an analysis of the musical context of part of these places.

We have performed hypothesis tests to compare the available data in several ways. Depending on the exploratory nature of the study, for each pair of data A, B, we established two hypotheses, with their respective null (H0) and alternative (H1) hypotheses:

First hypothesis:

$\mathrm{H} 0$ : values of $A>=$ values of $B$

H1: A values $<$ B values

Second hypothesis:

H0: values of $\mathrm{A}<=$ values of $\mathrm{B}$

H1: A values $>$ B values

From the results of these tests, we performed an analysis of the involved musical context involved to achieve a better understanding of its meaning.

Finally, we studied the contours of all attributes of all section-objects and verified similarity indices, reduced contour profiles, and the location of maximum and minimum points of this data.

\subsection{Analysis of musical context}

Statistical studies resulted in information that demanded a further investigation of the musical context of several sections, such as outliers in an 
A quantitative study of pitch registers in string quartets opus 17 , by Joseph Haydn

instrument register or amplitude values in one section too low beside another section. Many of these cases were verified individually.

The analysis consisted of verifying relations between registers and musical aspects such as formal segmentation points - such as phrase segmentschanges in harmonic rhythm, in rhythmic patterns and textures, composition, and extreme points preparation/resolution techniques.

In the case of outliers, the objective of the context analysis was to verify the possible musical importance of these values for the analyzed section or movement.

\section{Outliers}

We performed the study of the atypical values with data of sonorities' amplitude and instruments' pitches. These values were calculated based on two types of data collection: from the whole movement (union of section-object data of each movement) and each formal section. The detected outliers in the entire movement are, of course, more widespread. The detected values in the formal sections are more specific and local. In addition to identifying outliers, we found their occurrence in the works and have studied the musical context involved.

\subsection{Outliers in the amplitude of vertical sonorities}

The calculation of atypical values of the sonorities' amplitude in the context of the movements returned 33 occurrences, according to Table 5. These points occurred in eight movements, in situations such as melodic apex, apex at the end of a sentence, beginning of section, and texture segmentation.

\begin{tabular}{lr} 
& High \\
\hline op17n1-01 & 3 \\
op17n1-04 & 6 \\
op17n2-01 & 4 \\
op17n2-03 & 6 \\
op17n2-04 & 11 \\
op17n4-01 & 3 \\
\hline
\end{tabular}

Table 5: Number of outliers occurrences of vertical sonorities' amplitude in each movement. Source: authors 
MUSICA THEORICA Revista da Associação Brasileira de Teoria e Análise Musical 2020,

v. 5, n. 1, p. 119-177 - Journal of the Brazilian Society for Music

The calculation of amplitude outliers in the context of the sections returned 143 occurrences in nine sections, as shown in Table 6. Only op17n2-03 and op17n4-04 sections did not exhibit outliers from section's data.

\begin{tabular}{lrrr} 
& Low & High & Total \\
Section & & & \\
\hline E.T1 & 2 & 2 & 4 \\
E.Tr & 5 & 8 & 13 \\
E.T2 & 16 & 14 & 30 \\
E.CT & 13 & 3 & 16 \\
D & 27 & 14 & 41 \\
R.T1 & 8 & 11 & 19 \\
R.Tr & 0 & 7 & 7 \\
R.T2 & 2 & 3 & 5 \\
R.CT & 7 & 1 & 8 \\
Total & 80 & 63 & 143
\end{tabular}

Table 6: Number of occurrences of vertical sonorities' amplitude outliers in the sections grouped by type. Source: authors.

Many of these outliers occur in successive measures of the same movement section. For example, 12 of the 14 high outliers in E.T2 sections occur in the op17n2-04 movement (Ex. 2). In this section, there is a tendency for an amplitude of just over an octave. However, there are several occurrences of amplitudes larger than two and a half octaves. At the beginning of the section, values of high-value amplitude mark the construction of a scale in the low register, in the long run. At the end of the section, it marks high points.

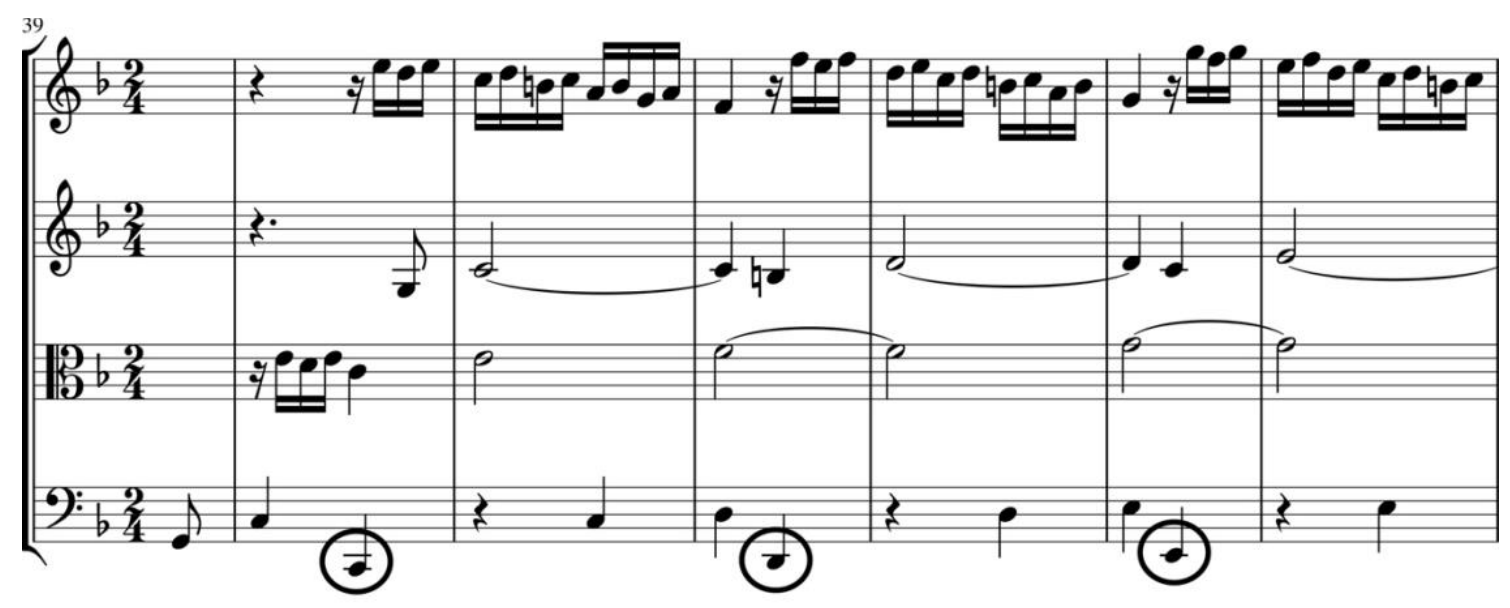


A quantitative study of pitch registers in string quartets opus 17 , by Joseph Haydn
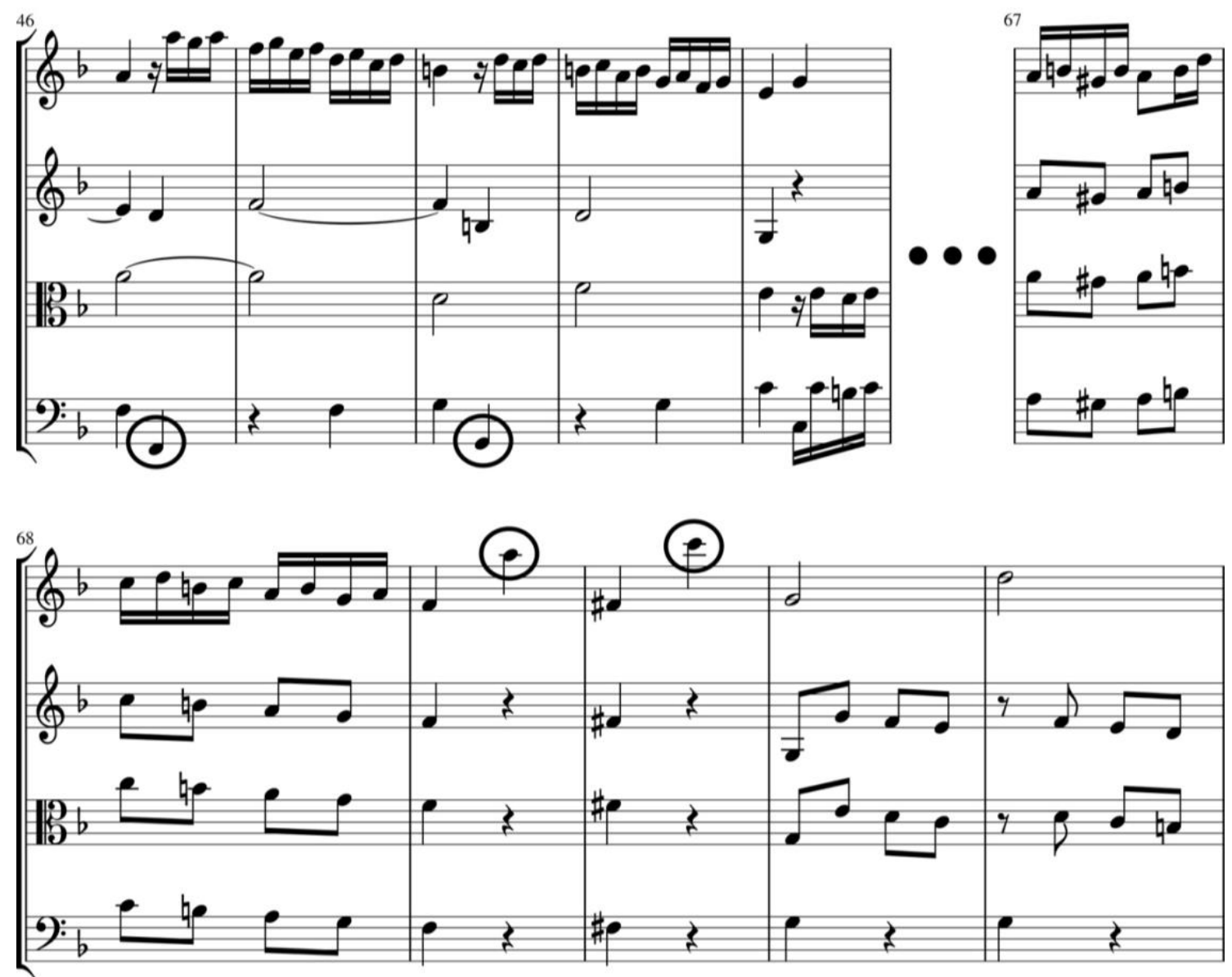

Example 2: Section E.T2 of the op17n2-04 movement (m. 39-50 and 67-72); Source: authors

Likewise, 11 of the 27 low outliers in Development sections occur in the op17n6-01 movement. These extremes are the result of passages with a solo on the first violin and rest on the others.

\subsection{Outliers on the instruments' pitches}

We detected outliers on all instruments' pitches, in a study involving all the data in the corpus, as shown in the graph in Fig. 6. 
MUSICA THEORICA Revista da Associação Brasileira de Teoria e Análise Musical 2020,

v. 5, n. 1, p. 119-177 - Journal of the Brazilian Society for Music

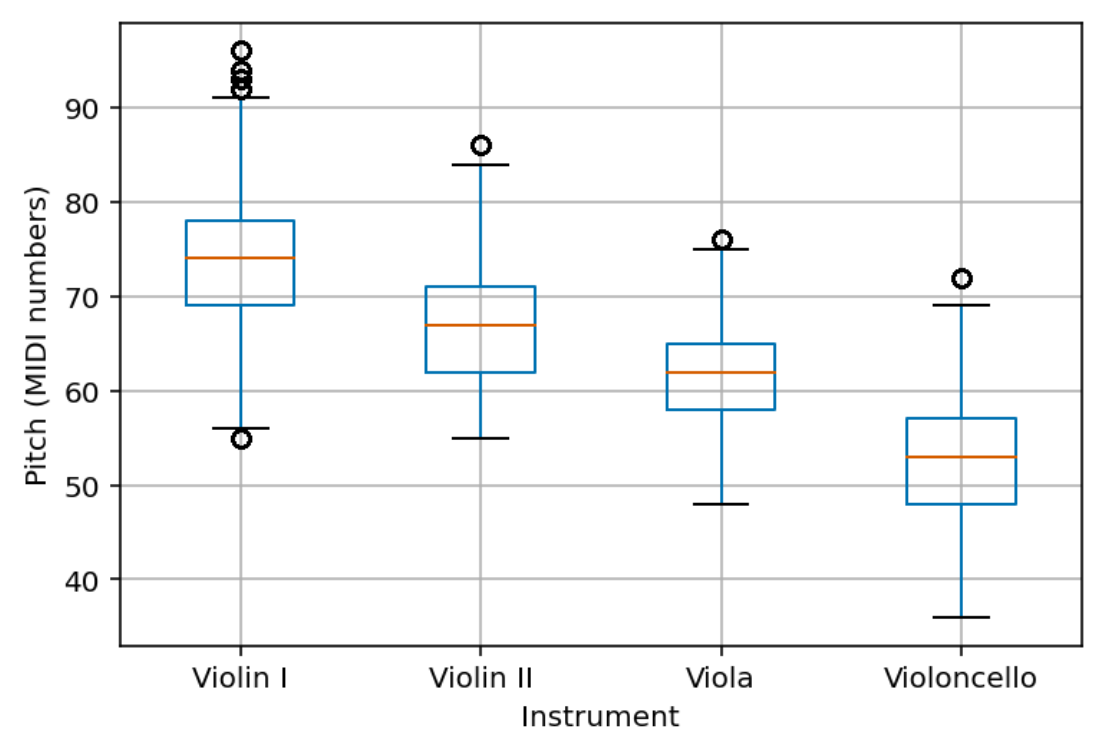

Figure 6: Distribution of the instruments' pitch values throughout the corpus. Source: authors

In a slightly more in-depth study, we identified 115 occurrences of atypical values of instruments' pitches in the context of individual movements, as shown in Table 7. The first violin and violoncello concentrate most of the occurrences of outliers $-36.5 \%$ on the first violin and $43.5 \%$ on the violoncello. The musical context analysis of these points revealed that, in general, there is a relation between the outliers and form segmentation.

\begin{tabular}{lrrr}
\hline & Low & High & Total \\
\hline Violin I & 28 & 14 & 42 \\
Violin II & 0 & 4 & 4 \\
Viola & 14 & 5 & 19 \\
Violoncello & 39 & 11 & 50 \\
\hline
\end{tabular}

Table 7: Number of occurrences of instruments' pitch outliers in the data per movement. Source: authors.

In a more in-depth study, referring to the context of the individual sections, we detected 508 occurrences of outliers, distributed according to Table 8 and Fig. 7. We observed that the development section concentrates the highest number of occurrences, with emphasis on high values on the first violin. 
A quantitative study of pitch registers in string quartets opus 17, by Joseph

Haydn

\begin{tabular}{lrrrrrrrrr} 
& V1 L & V1 H & V2 L & V2 H & Va L & Va H & Vc L & Vc H & Total \\
\hline E.T1 & 3 & 6 & 5 & 6 & 4 & 9 & 3 & 4 & 40 \\
E.Tr & 8 & 10 & 2 & 7 & 10 & 6 & 11 & 7 & 61 \\
E.T2 & 9 & 2 & 0 & 12 & 4 & 5 & 26 & 11 & 69 \\
E.CT & 7 & 5 & 5 & 5 & 3 & 4 & 5 & 11 & 45 \\
D & 27 & 4 & 8 & 10 & 18 & 11 & 14 & 4 & 96 \\
R.T1 & 10 & 2 & 8 & 1 & 7 & 3 & 5 & 6 & 42 \\
R.Tr & 3 & 1 & 1 & 2 & 2 & 1 & 8 & 3 & 21 \\
R.T2 & 7 & 7 & 16 & 12 & 7 & 10 & 9 & 0 & 68 \\
R.CT & 11 & 6 & 5 & 5 & 1 & 8 & 11 & 8 & 55 \\
C & 0 & 0 & 0 & 3 & 0 & 0 & 4 & 4 & 11 \\
Total & 85 & 43 & 50 & 63 & 56 & 57 & 96 & 58 & 508 \\
\hline
\end{tabular}

Table 8: Number of outliers for instrument pitches in sections grouped by section type. The " $\mathrm{L}$ " and " $\mathrm{H}$ " signs beside each instrument abbreviation inform whether the value is lower than or higher than the rest of the distribution. Source: authors

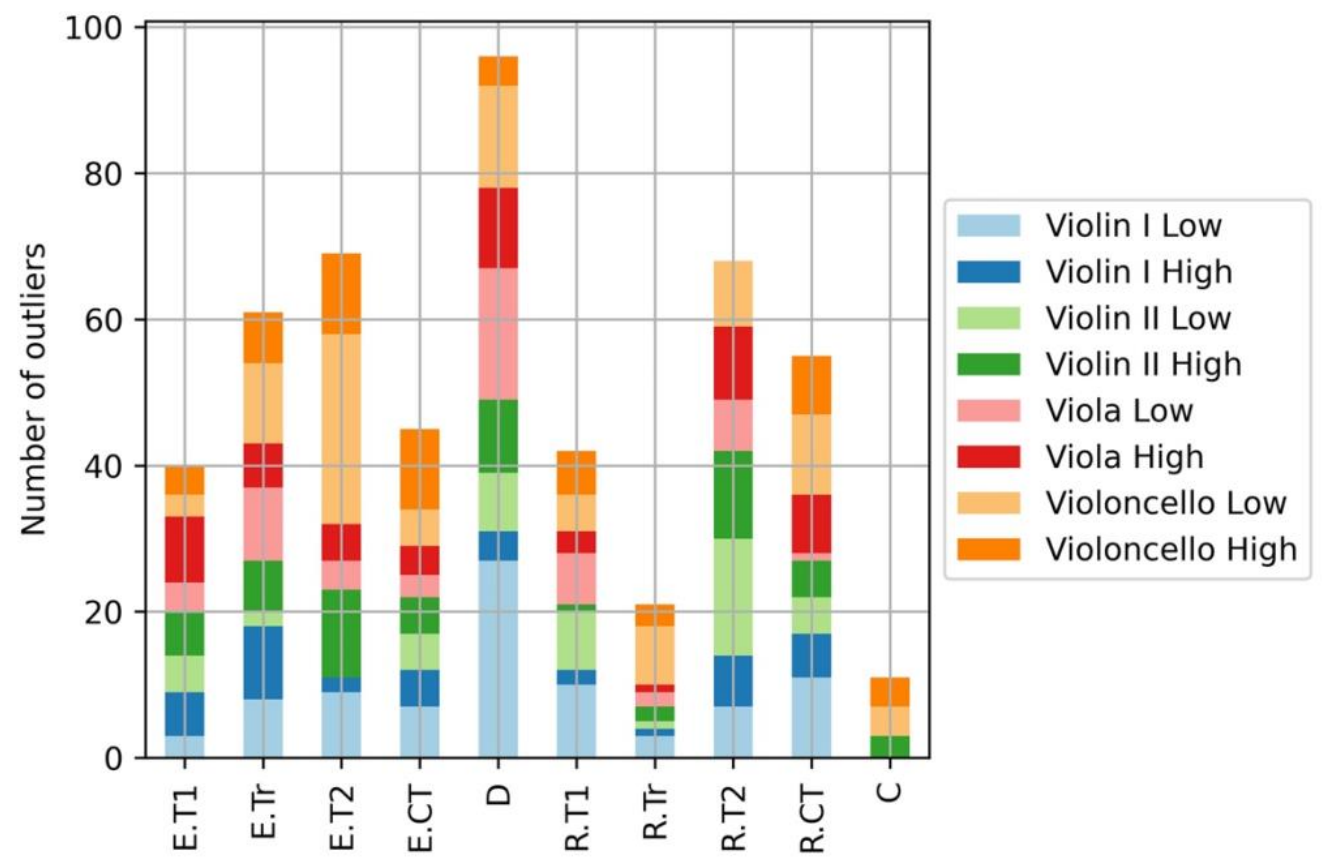

Figure 7: Number of outliers for instrument pitches in sections grouped by section type. The "Low" and "High" signs beside each instrument abbreviation inform whether the value is lower than or higher than the rest of the distribution. Source: authors

We collected a random sample of 80 occurrences of outliers at the pitches of the instruments and performed a manual analysis of the musical context of 
MUSICA THEORICA Revista da Associação Brasileira de Teoria e Análise Musical 2020,

these cases. It was possible to identify categories of music characteristics associated with these extreme values:

- Finalization of the formal section

- A split point between phrases or phrase segments

- Melodic apex (both high and low)

- Texture change

- Rhythmic change

- Change in harmonic pattern

- Harmonic/orchestral support

- Motivic/compositional structure

- Imitation interplay/answers

The association between extreme pitch values and completion of a formal section can be observed, for example, in the voice of the first violin, at the end of the R.T2 section, of the op17n1-03 movement (Ex. 3). In this case, the extreme value is the final note, $\mathrm{D}^{\prime}(\mathrm{m} .73)$.

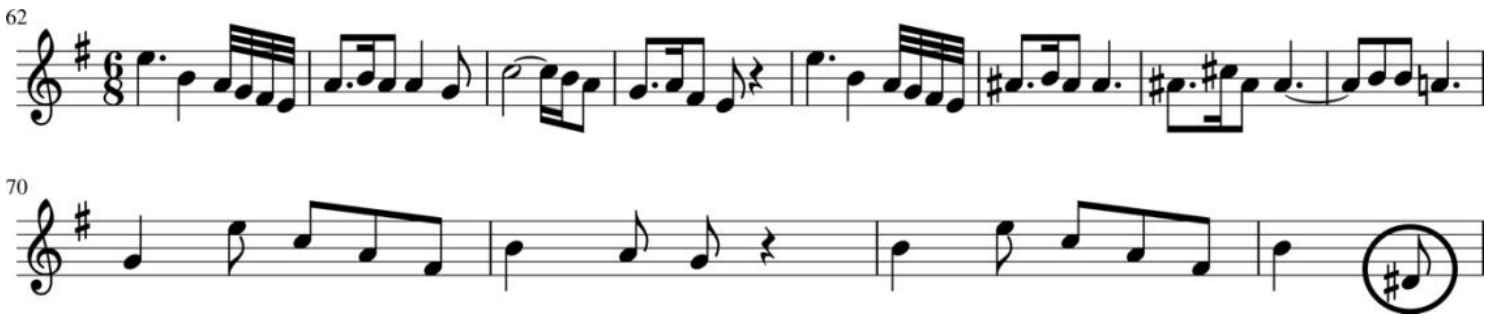

Example 3: Part of the first violin in the op17n1-03 movement's R.T2 section (m. 62-73); Source: authors

The E.Tr section of the op17n4-01 movement is an example of the use of extreme value as a support for form segmentation. From the high F (m. 15) on, the second phase of the transition begins ${ }^{9}$ (Ex. 4). This excerpt is also an example of a change in the harmonic pattern.

\footnotetext{
${ }^{9}$ Douglass Green (1979, p. 184) proposes a subdivision of the transition section of the Sonata Exposition into three phases: a) Keeping the tonic, b) tonicizing the dominant, and c) tonicizing the dominant's dominant.
} 
A quantitative study of pitch registers in string quartets opus 17 , by Joseph Haydn
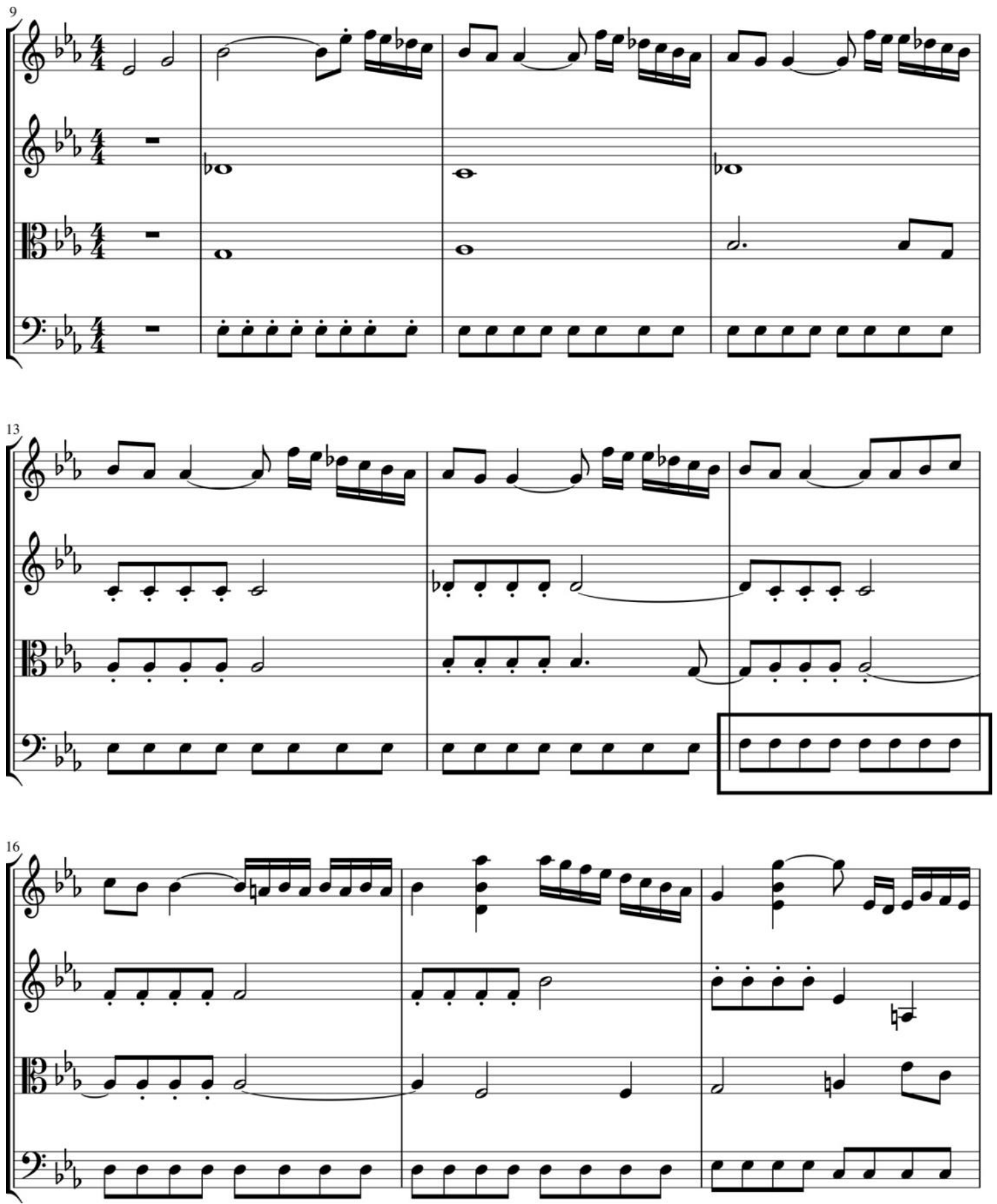
MUSICA THEORICA Revista da Associação Brasileira de Teoria e Análise Musical 2020, v. 5, n. 1, p. 119-177 - Journal of the Brazilian Society for Music

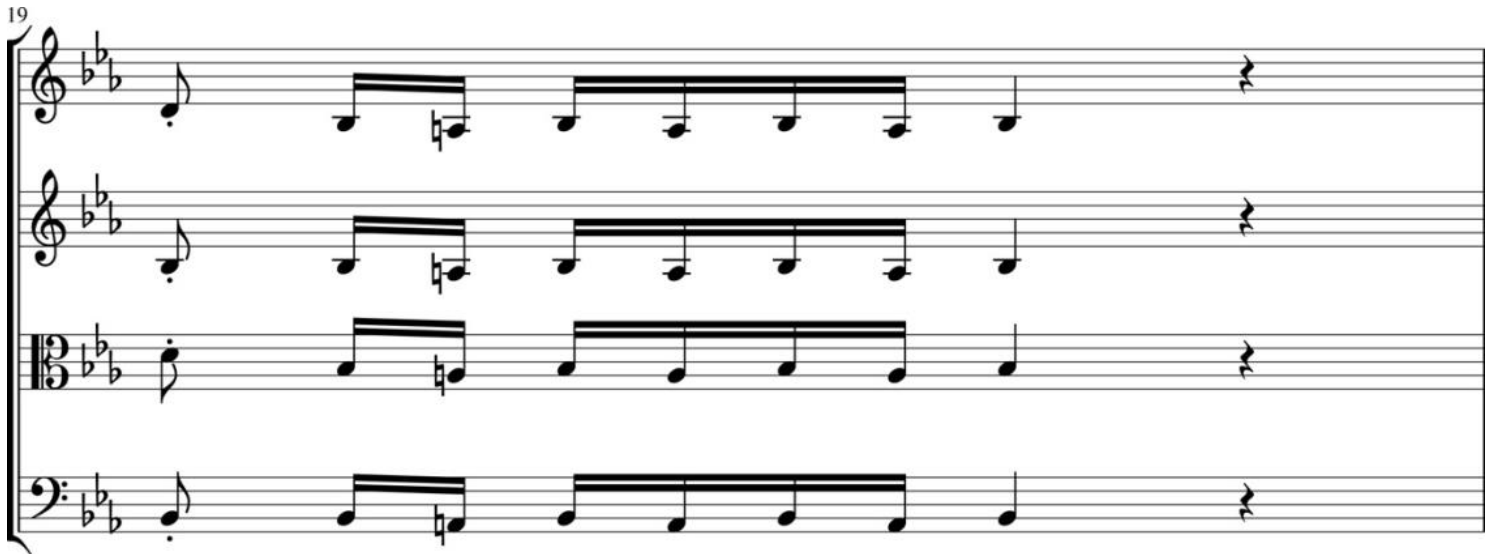

Example 4: E.Tr section of the op17n4-01 movement (m. 9-19); Source: authors

In the viola part of section R.T2 of the op17n4-04 movement, there is an upward transposition process with the motif until it reaches its apex in the note $\mathrm{E} \square$ (m. 86), featuring the use of outliers as a melodic apex.

81

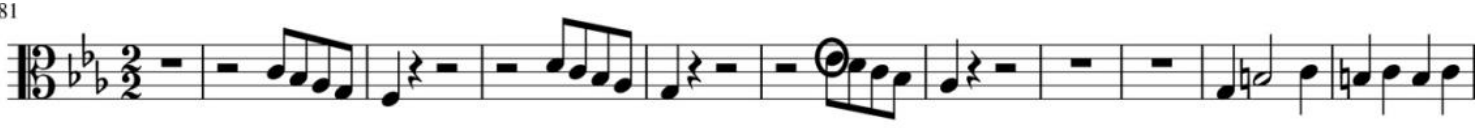

92

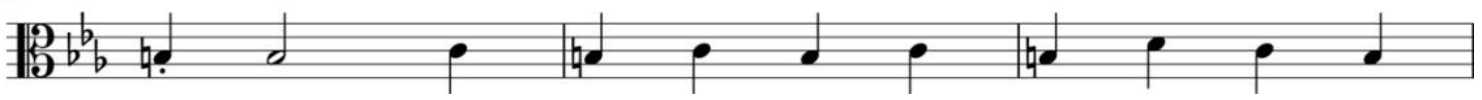

Example 5: Part of the viola in section R.T1 of the op17n4-04 movement (m. 81-94); Source: authors

The R.T2 section of the op17n6-04 movement illustrates the association between extreme values and texture changes, at all points where the low $\mathrm{D}$ notes occur on the violoncello (Ex. 6, m. 132, 135 and 136).

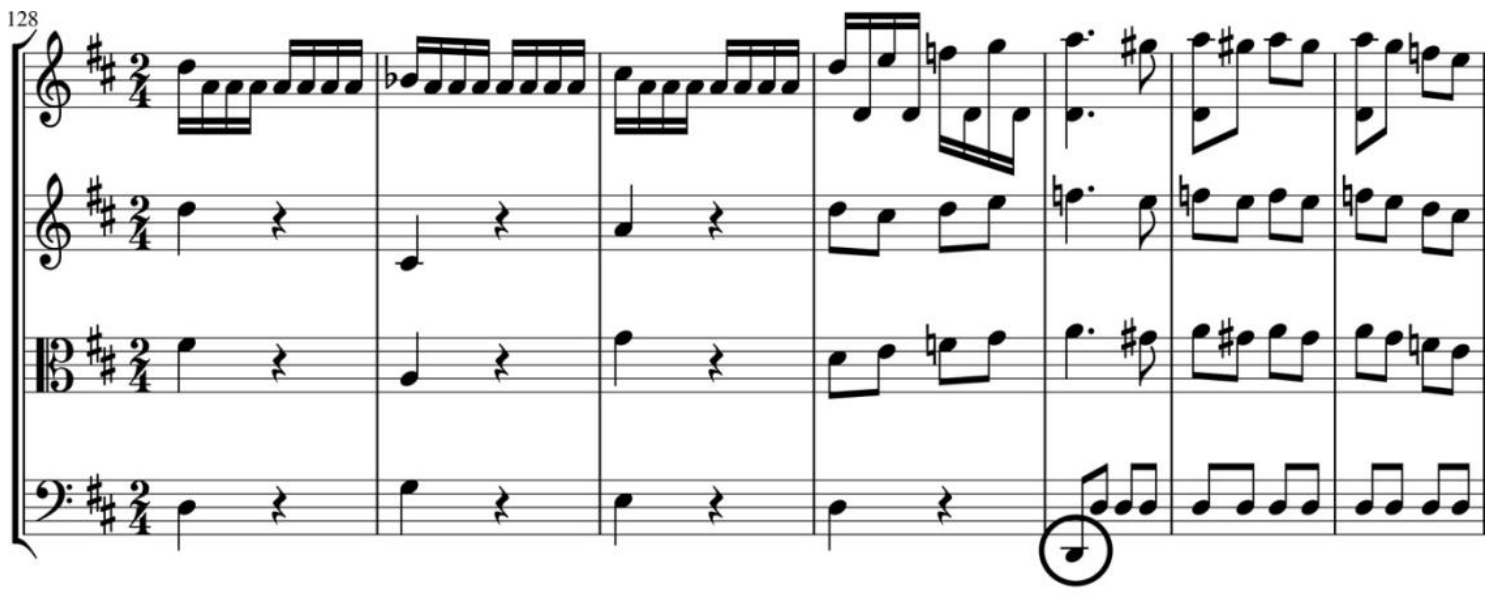


A quantitative study of pitch registers in string quartets opus 17, by Joseph Haydn

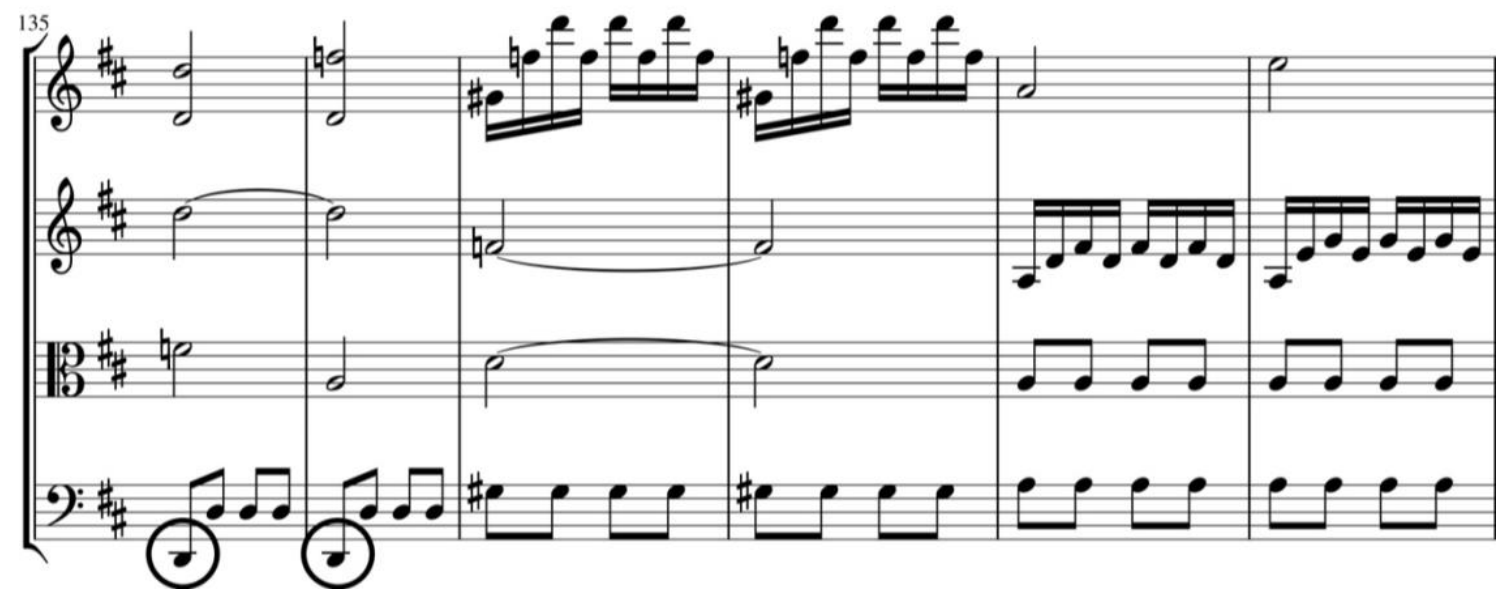

Example 6: Section R.T2 of the op17n6-04 movement (m. 128-140); Source: authors

In the E.CT section of the op17n4-04 movement, the note E $\square$ occurs on the viola twice, subtly coinciding with the end of the textural design (Ex. 7, m. 40-41 and 45).
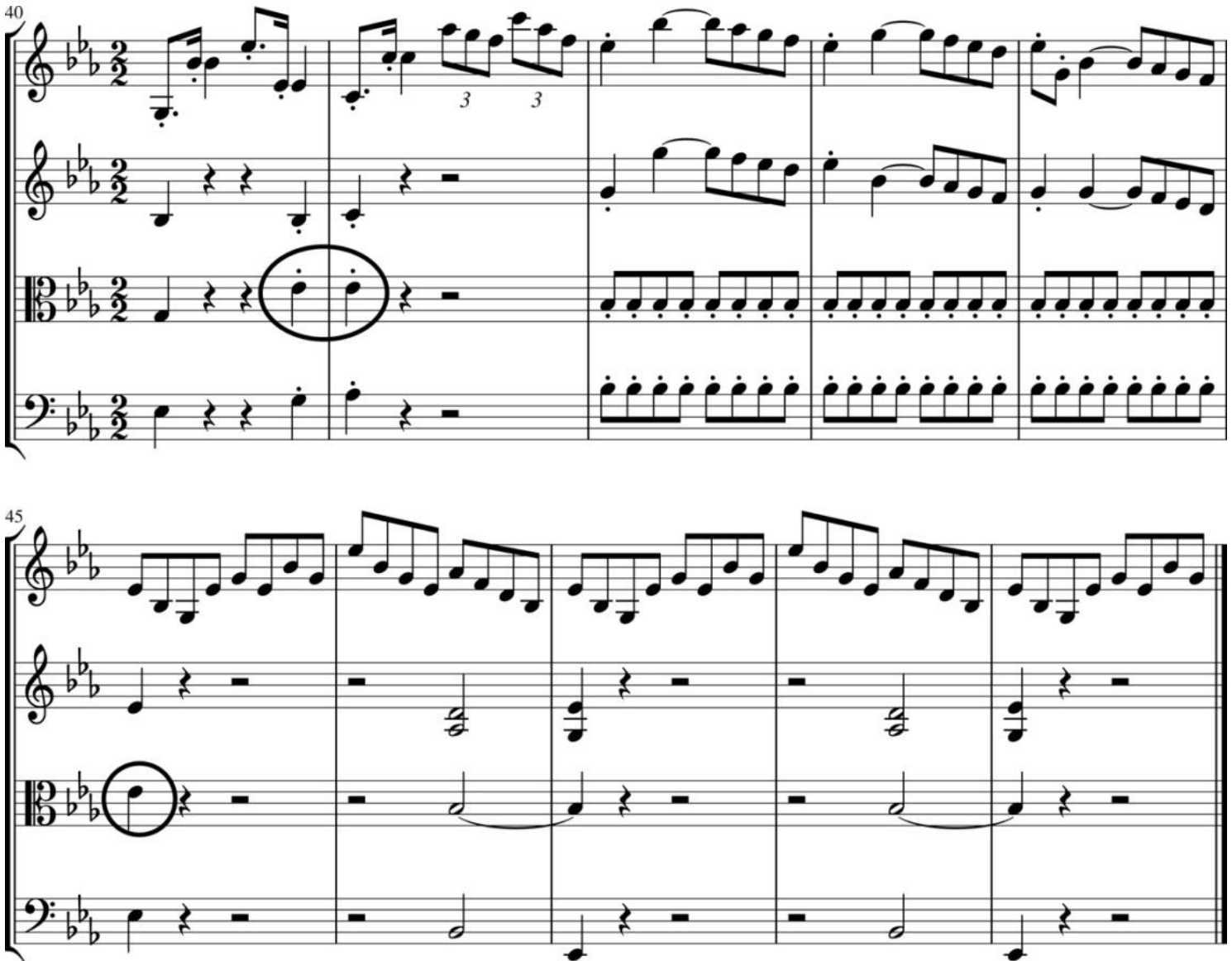

Example 7: E.CT section of the op17n4-04 movement (m. 40-49); Source: authors 
MUSICA THEORICA Revista da Associação Brasileira de Teoria e Análise Musical 2020,

The violin part in the E.T1 section of the op17n5-04 movement is an example of extreme value associated with rhythmic change (Ex. 8, m. 17).

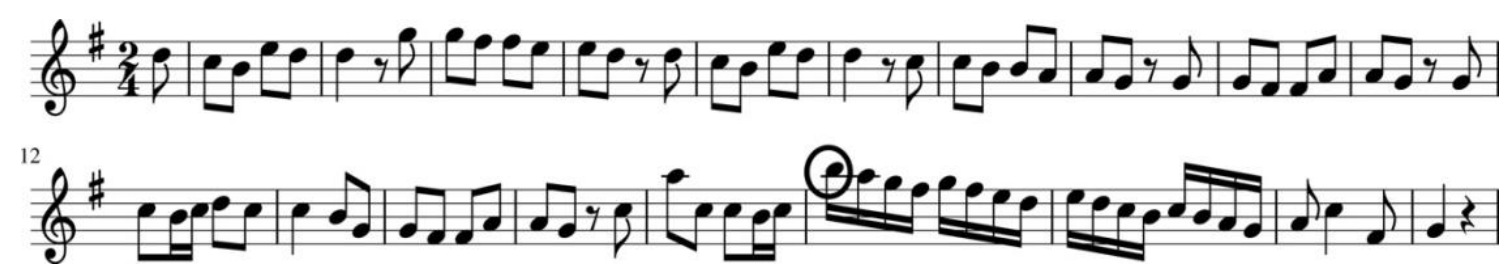

Example 8: Part of the first violin in the E.T1 section of the op17n5-04 movement (m. 120). Source: authors

In the first violin part, in the E.T2 section of the op17n2-03 movement, there are two occurrences of extremely low value, the low A. This is a case of motivic use of extremes (Ex. 9, m. 24 and 26).
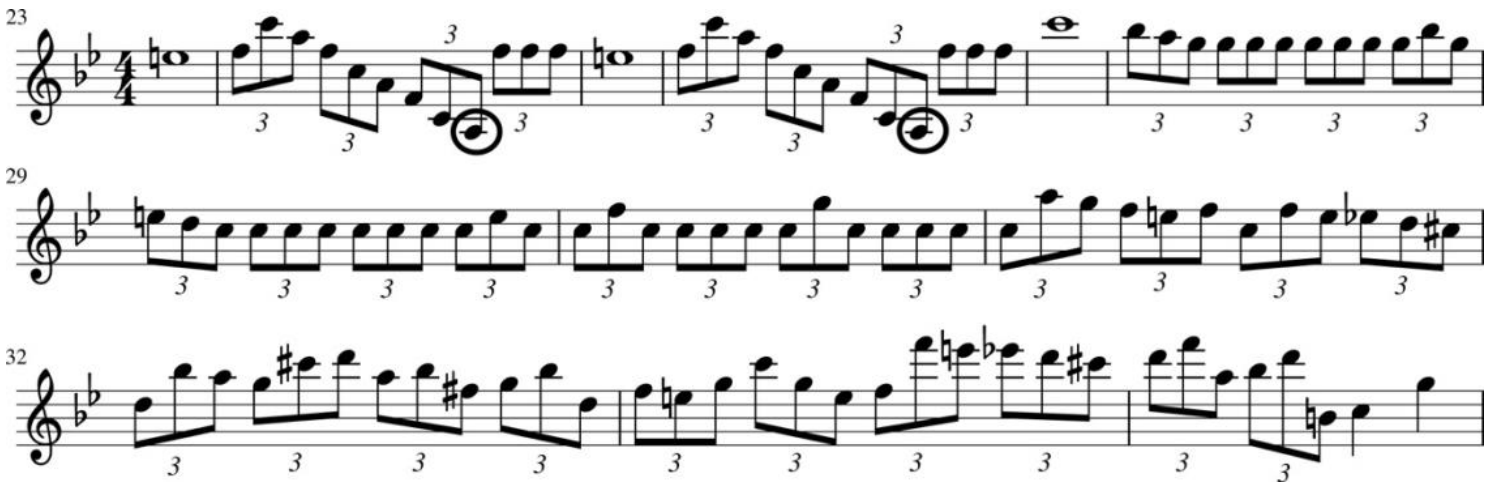

Example 9: Part of the first violin, in section E.T2 of the op17n2-03 movement (m. 23-

34); Source: authors

In the development section of the op17n4-01 movement, the high $\mathrm{C}$ in the viola part is an example of using extremes to support orchestration. It is interesting to note that, in this location, the voice of the viola is between those of the two violins (Ex. 10, m. 61). 
A quantitative study of pitch registers in string quartets opus 17 , by Joseph Haydn
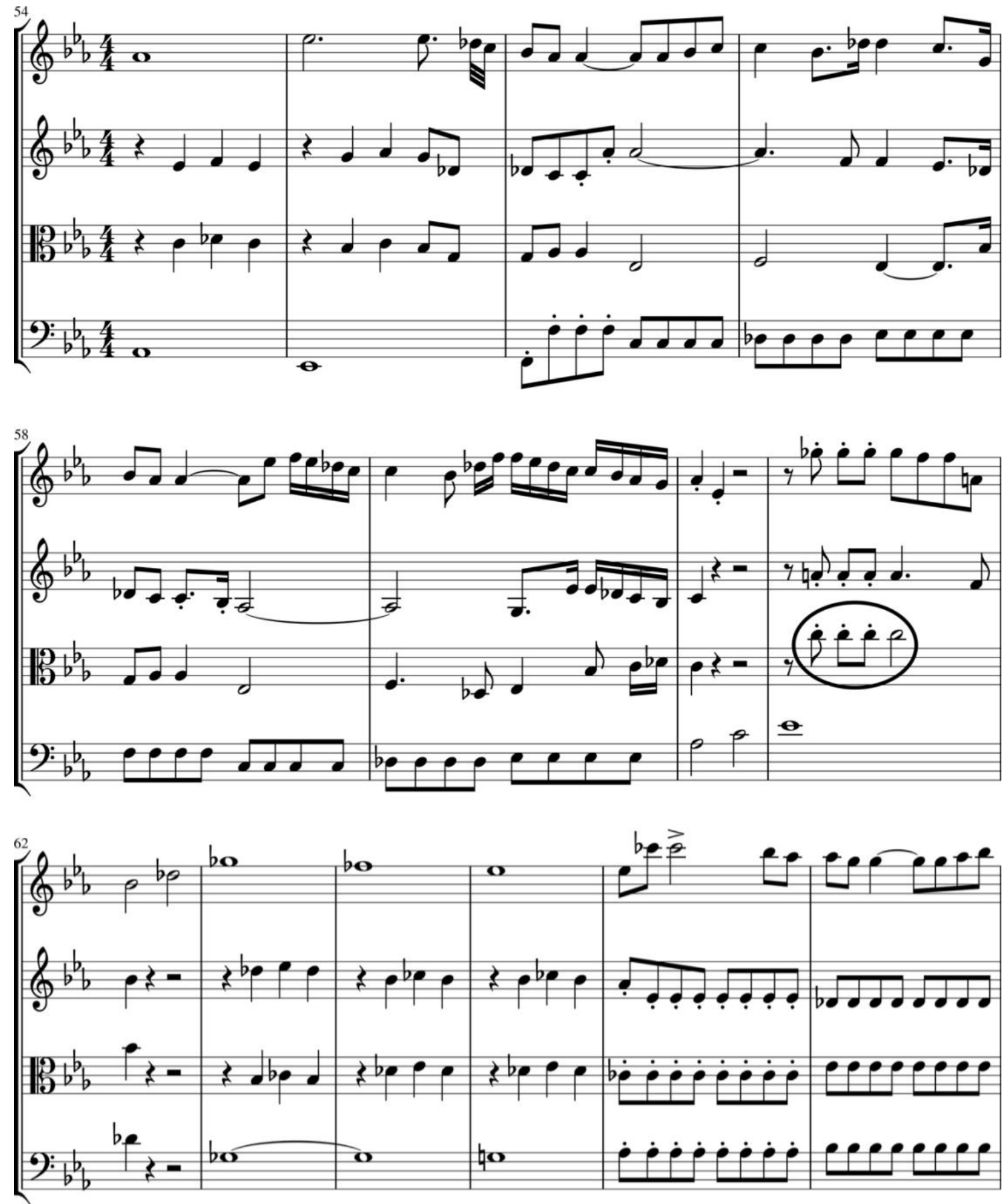

Example 10: Op17n4-01 movement's Development section beginning (m. 54-67); Source: authors

In the viola part of the op17n6-01 movement's E.Tr section, the highest pitches are used in conjunction with the violoncello voice always responding to the violins parts (Ex. 11, m. 16-19). 
MUSICA THEORICA Revista da Associação Brasileira de Teoria e Análise Musical 2020, v. 5, n. 1, p. 119-177 - Journal of the Brazilian Society for Music
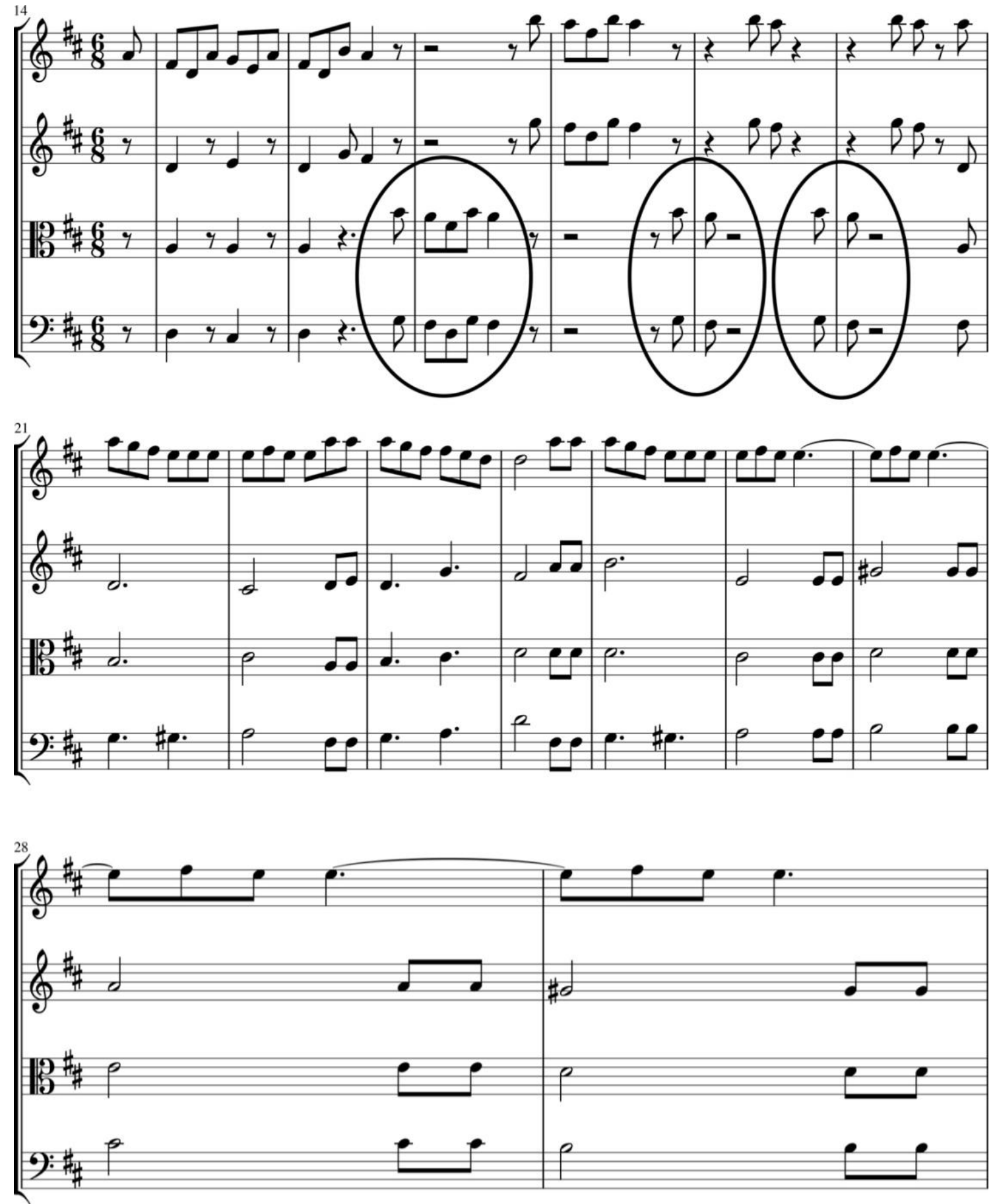

Example 11: Op17n6-01 movement's E.Tr section (m. 14-29); Source: authors

In the op17n2-01 movement's R.T2 section, the atypical $\mathrm{B} \square$ pitch, in the viola voice, is an example of an imitation interplay with the violoncello voice (Ex. $12, \mathrm{~m} .82$ and 84 ). In this example, this note has an additional particularity for the sonority, as it is the seventh of the dominant chord, in the third inversion, resolving in the A pitch next. 
A quantitative study of pitch registers in string quartets opus 17, by Joseph Haydn
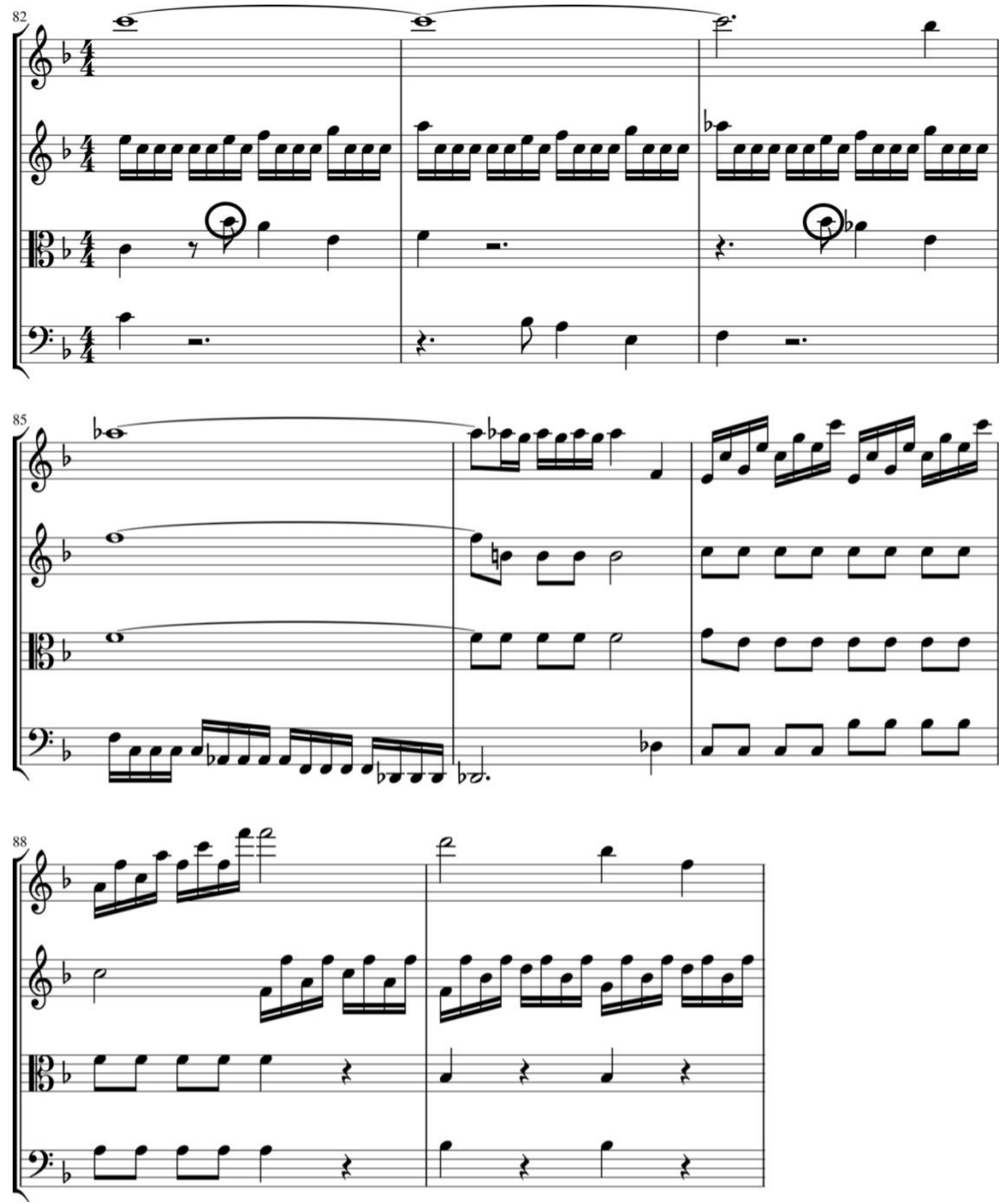

Example 12: Op17n2-01 movement's R.T2 section (m. 82-86); Source: authors

In the voice of the violoncello, the atypical values can coincide with harmonic support or other functions performed by the bass. 


\section{Comparisons between data from different sections}

In this paper, we performed comparative studies of all available values: the vertical sonorities' amplitude, the pitches of each instrument, and the contours of each of these data. We divided these studies into three parts: comparison between the data of each section type and its complement, between section-objects pairs, and between the contours of these matched pairs data (see details about the comparison types in section 3.2).

\subsection{Sonorities' amplitudes and instrument pitches (section type $x$ its complement)}

We performed comparative studies between the vertical sonorities' amplitude values of each section type and of their respective complementary sections (for instance, between the Development section and all other sections' data. See section 3.2 for details about comparison strategy). For each of these studies, we created two data sets: with the amplitude values of all the sectionobjects of a given section type, and with the amplitude values of the sectionobjects complementary to this section type. We have used the joining procedure described in section 3.2 to group the data for each section-object in these sets.

For each of the ten section types, we have proceeded with exploratory hypothesis tests with the respective value pairs sets - data for a section type and data for its complement. These tests showed 1) that the development and second theme sections (both in the exposition and recapitulation) have larger amplitude values than their complements, and 2) that, individually, all other section types (E.T1, E.Tr, E. CT, R.T1, R.Tr, R.CT, and C) have lower amplitude values than their respective complements.

We used the same strategy to compare the pitch values of each instrument. Thus, we performed 40 tests, one for each section type for each instrument. This study showed that, in all instruments, the pitches are higher in the development, the exposition of the second theme, and the retransition sections than in their respective complements (see Table 9). Similarly, in all instruments, the pitches are lower in the first theme (both in the exposition and recapitulation), concluding theme and coda sections than in their respective complements. In the recapitulation of the second theme, the pitches are higher than the sections set only in the violins and viola. 
A quantitative study of pitch registers in string quartets opus 17, by Joseph

Haydn

\begin{tabular}{lllll} 
& Violin I & Violin II & Viola & Violoncello \\
Section & & & & \\
\hline E.T1 & Less & Less & Less & Less \\
E.Tr & Less & Less & Less & Greater \\
E.T2 & Greater & Greater & Greater & Greater \\
E.CT & Less & Non-conclusive & Less & Less \\
D & Greater & Greater & Greater & Greater \\
R.T1 & Less & Less & Less & Less \\
R.Tr & Greater & Greater & Greater & Greater \\
R.T2 & Greater & Greater & Greater & Less \\
R.CT & Less & Less & Less & Less \\
C & Less & Less & Less & Less \\
\hline
\end{tabular}

Table 9: Test results for comparing instrument pitch values between section type and section complements; Source: authors

Both results, of the vertical sonorities' amplitude values of and instrumental pitches, corroborate the expectations of the contrast of the second theme and development sections with the others.

\subsection{Sonorities' amplitudes and instrument pitches (section $\mathrm{x}$ section)}

In a more detailed analysis, we made comparative studies of the data of combined section-objects pairs belonging to the same movement, in a comparison procedure 1-1 (see section 3.2). We have performed 840 exploratory hypothesis tests on the vertical sonorities' amplitude values for each matched pair and have grouped the conclusive results by section type, for further analysis.

We have looked more closely at three types of combination pairs: between first and second themes, between the occurrence of sections in the exposition and the recapitulation (for instance, E.T1 and R.T1), and between adjacent sections (for example, E.T1 and E.Tr). We have summarized the conclusive exploratory tests results in Table 10. The "Lesser" column represents the number of conclusive tests where the values of "Section 1" are lesser than those of "Section 2 ". For instance, there are nine conclusive tests where the amplitude values of E.T1 section are lesser than those of E.T2 (first row). The "greater" column represents the opposite. 
MUSICA THEORICA Revista da Associação Brasileira de Teoria e Análise Musical 2020,

v. 5, n. 1, p. 119-177 - Journal of the Brazilian Society for Music

Theory and Analysis @ TeMA 2020 - ISSN 2525-5541

\begin{tabular}{lllrr}
\hline & Section 1 & Section 2 & Less & Greater \\
\hline 1 & E.T1 & E.T2 & 9 & 3 \\
2 & R.T1 & R.T2 & 9 & 3 \\
3 & E.T1 & R.T1 & 5 & 6 \\
4 & E.Tr & R.Tr & 0 & 3 \\
5 & E.T2 & R.T2 & 6 & 6 \\
6 & E.CT & R.CT & 4 & 4 \\
7 & E.T1 & E.Tr & 5 & 5 \\
8 & E.Tr & E.T2 & 7 & 2 \\
9 & E.T2 & E.CT & 5 & 7 \\
10 & E.CT & D & 8 & 5 \\
11 & D & R.T1 & 4 & 8 \\
12 & R.T1 & R.Tr & 0 & 3 \\
13 & R.Tr & R.T2 & 3 & 1 \\
14 & R.T2 & R.CT & 2 & 9
\end{tabular}

Table 10: Number of movements in which there are conclusive results after comparing the sonorities' amplitude values section types of pairs; Source: authors

In most tests done on these sections' pairs, we have noticed a balance in the relationship between the number of movements with a lower and higher value. The values of the pair's first section (section 1 column) are lower than the pair's second section (section 2 column) in about half of the conclusive tests. The other half has a reversed result. For example, on the pair E.T1-R.T1, there is evidence that the E.T1 section amplitude values are lower than those of the R.T1 section in five movements, and higher in six.

On the other hand, there is an imbalance in the relation of this number of movements in four pairs: E.T1-E.T2, R.T1-R.T2, E.Tr-E.T2, and R.T2-R.CT (ratio of $1: 4$ or more). We have realized that all these pairs contain second theme sections, both in the exposition and recapitulation. In all these cases, the number of movements in which the second theme's amplitude values is greater than in the other section (E.T1, R.T1, E.Tr, R.CT) is much greater than the opposite situation. Therefore, in most movements, there is an emphasis on the amplitude values of the second theme sections.

The comparative analysis of the musical context of the exposition's first and second theme sections revealed a higher complexity in the texture and the melodic development in the second theme sections, in comparison to the first ones. While the E.T1 section has as striking feature the exposure of the theme in a solo, duo, or accompanied melody, the E.T2 section is characterized by the use 
A quantitative study of pitch registers in string quartets opus 17, by Joseph Haydn

and interleaving of resources like secondary melodies, imitation segments, octave doublings, and repetitions.

We have observed that the rest measures in the violoncello part and the low-pitch first violin register cause amplitude values differences between these sections. These instrumental breaks are related to composition strategies such as fugato, imitation interplays, and solo melody with the intervention of the other instruments. For example, in the op17n3-04 movement, the first theme consists of a solo melody on the first violin, with an ending supported by other instruments (Ex. 13). Also, there is a predominance of the middle register in the voice of the first violin.

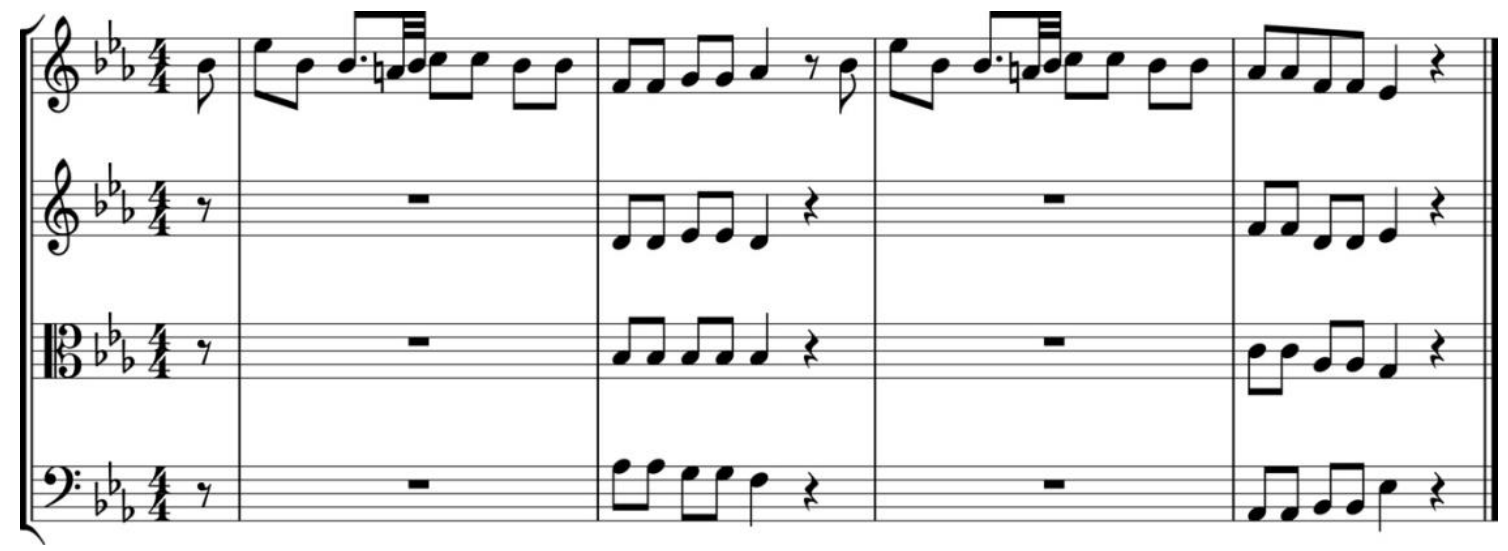

Example 13: Section E.T1 of the op17n3-04 movement (m. 1-4); Source: authors

In the second theme of this same movement (Ex. 14), despite the rest measures provided by the successive entries of the fugue-like procedure, there is a predominance of the use of the complete quartet. In comparison to the first theme, the voice of the first violin reaches higher registers, attaining the note $\mathrm{B} \square 6$. This example demonstrates Haydn's strategy in the treatment of a monothematic sonata, using different techniques and register choices in the themes to increase the contrast of tonality. 
MUSICA THEORICA Revista da Associação Brasileira de Teoria e Análise Musical 2020, v. 5, n. 1, p. 119-177 - Journal of the Brazilian Society for Music
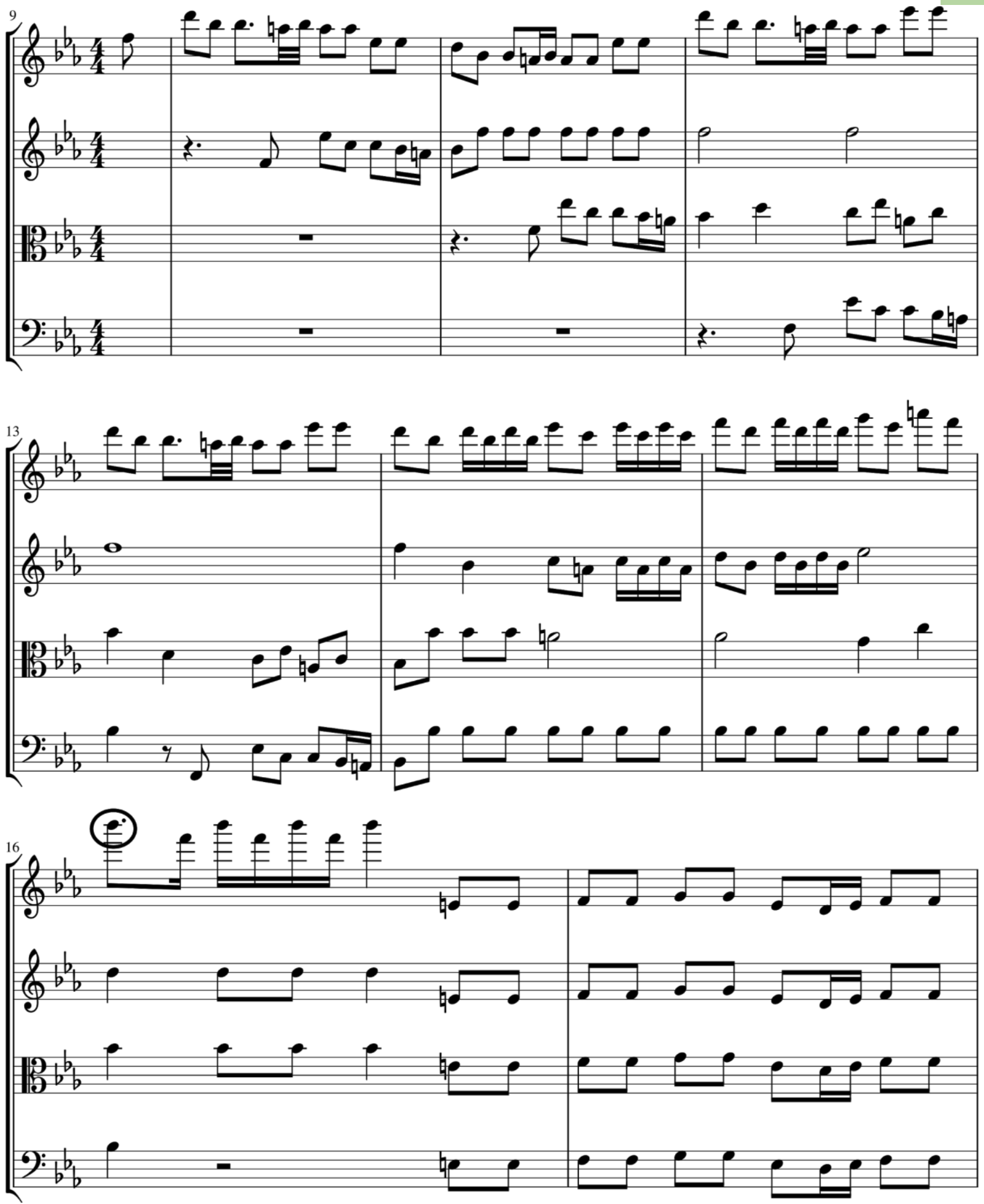

Example 14: E.T2 section of the op17n3-04 movement (m. 9-17); Source: authors

In only three of the movements with conclusive results (op17n2-01, op17n4-04, and op17n5-01), the first theme's sonorities' amplitude values were higher than those of the second one. In the op17n5-01 movement's second theme, 
A quantitative study of pitch registers in string quartets opus 17 , by Joseph

Haydn

there are a large number of measures with rests in the voice of the violoncello and viola, resulting in many low amplitude values in comparison to the first theme. The high-pitch register predominance in the violoncello part causes low sonorities' amplitude values in the op17n2-01 movement's second theme.

In the op17n04-04 movement, the first theme (Ex. 15) consists of three segments: the first, an interplay of questions and answers between violin and viola/violoncello duos; the second, a melody on the first violin accompanied by a homophonic rhythm on the other instruments; and the third a continuation of the previous melody, with doublings between the instruments. The second theme, in turn, consists of two segments: the first with pedal notes in the violoncello part, with low register predominance on the first violin, and the second, with alternation between solo fragments on the first violin and response on the other instruments (see Ex. 16). In this second theme, the other instruments are in rest, generating amplitudes of zero value, at the points where the first violin part reaches its highest notes. This construction gave rise to the result contrary to most movements, with higher amplitude values in the second theme than those of the first.

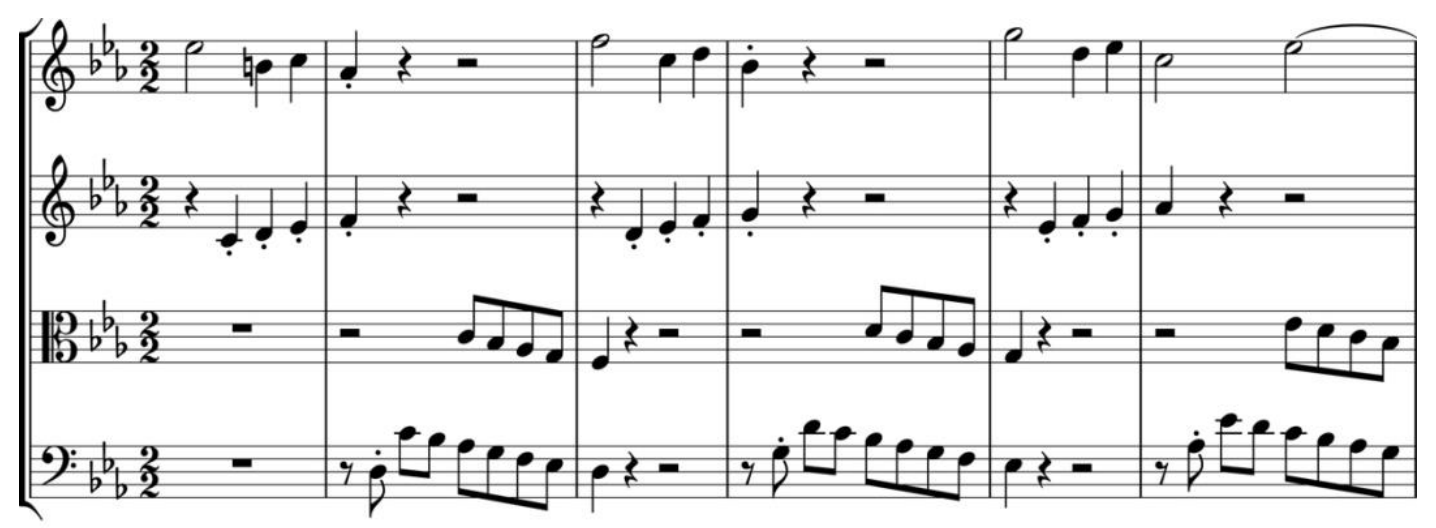


MUSICA THEORICA Revista da Associação Brasileira de Teoria e Análise Musical 2020, v. 5, n. 1, p. 119-177 - Journal of the Brazilian Society for Music
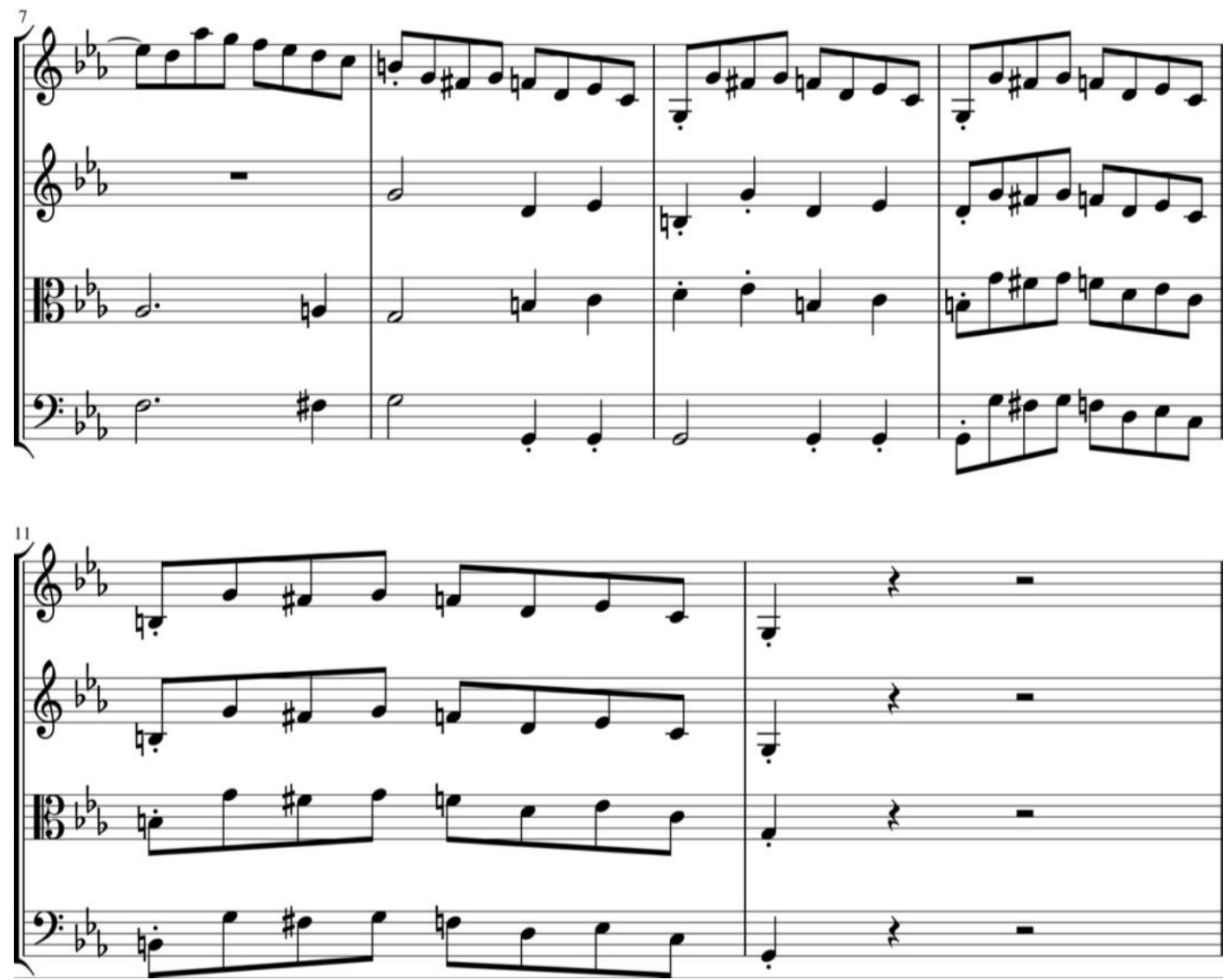

Exemplo 15: Section E.T1 of the op17n4-04 movement (m. 1-12); Source: authors

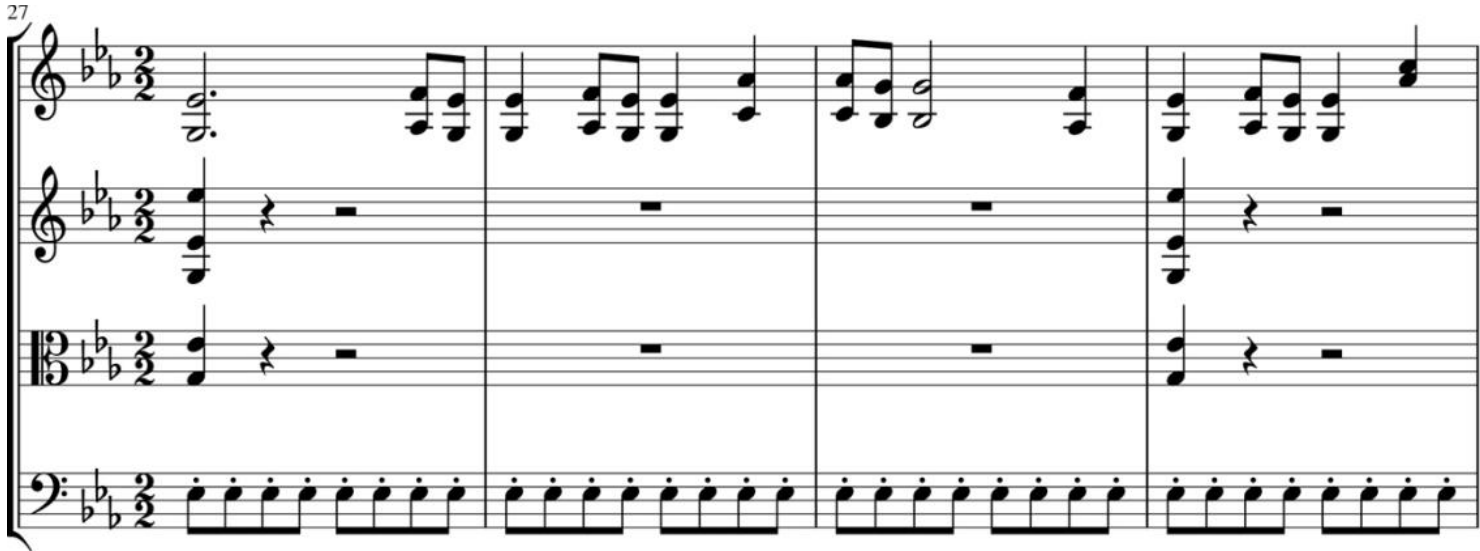


A quantitative study of pitch registers in string quartets opus 17 , by Joseph Haydn
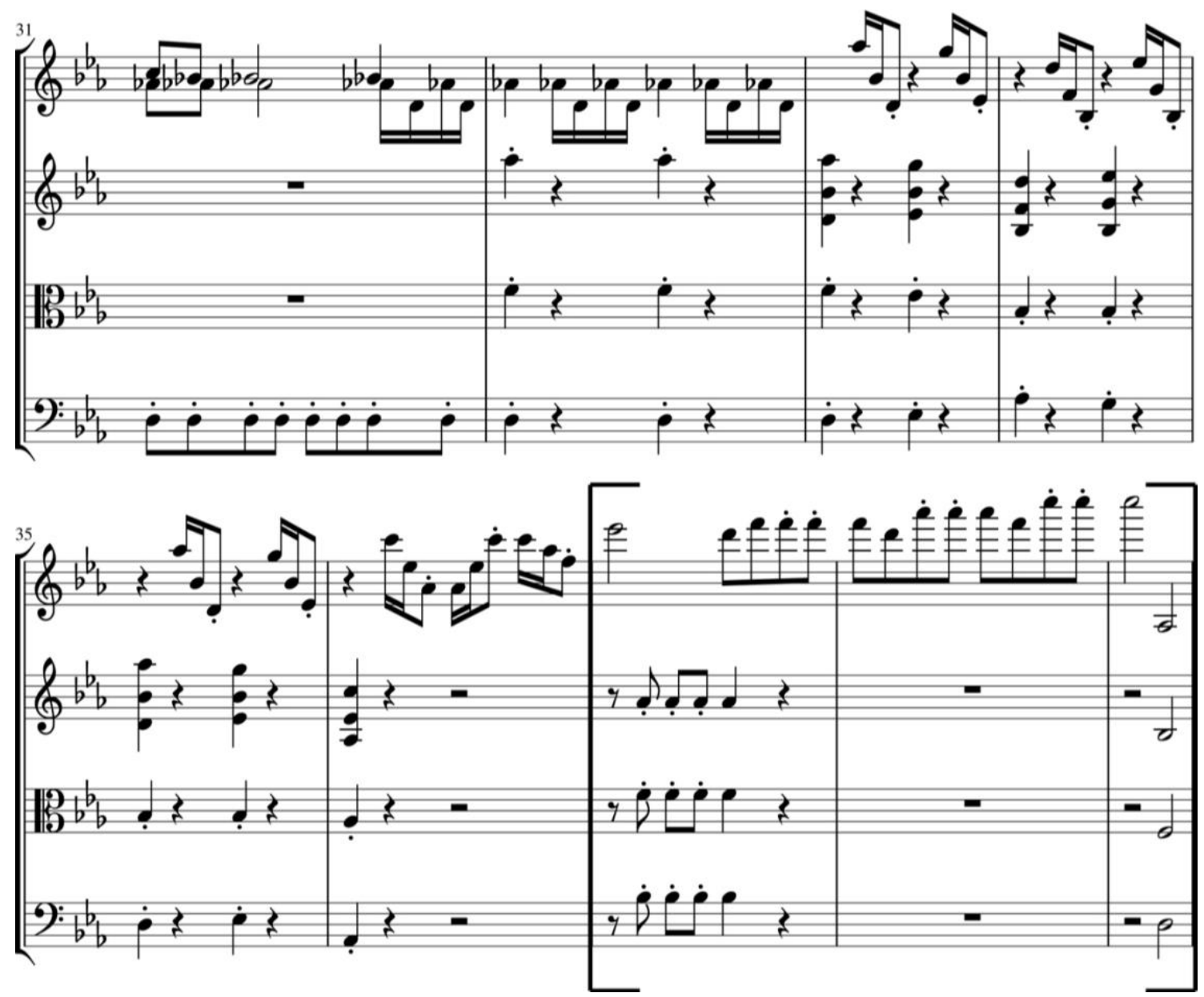

Example 16: Op17n4-04 movement's E.T2 section (m. 27-38); Source: authors

The amplitude histograms of these sections reveal 1) the impact that the solo passages cause in the E.T2 section values (Fig. 9) and the concentration around the octave interval in the third part of the E.T1 section (Fig. 8). 
MUSICA THEORICA Revista da Associação Brasileira de Teoria e Análise Musical 2020, v. 5, n. 1, p. 119-177 - Journal of the Brazilian Society for Music

Theory and Analysis@ TeMA 2020 - ISSN 2525-5541

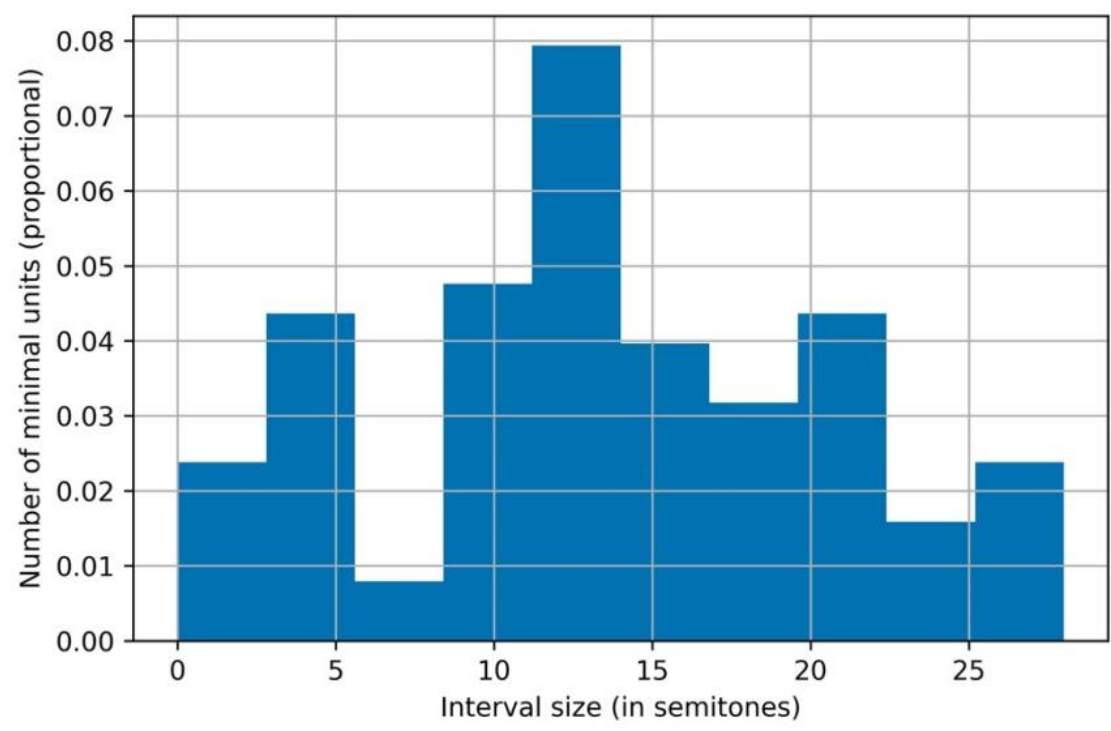

Figure 8: Distribution of the vertical sonorities' amplitude values of the op17n4-04 movement's E.T1 section; Source: authors

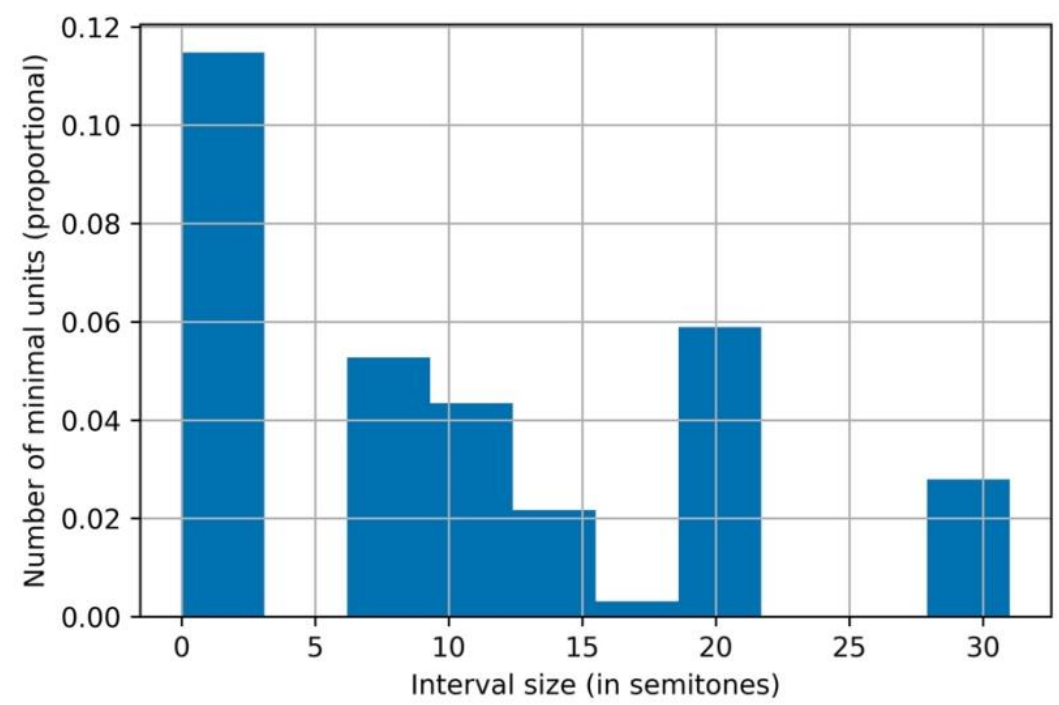

Figure 9: Distribution of the vertical sonorities' amplitude values of the op17n4-04 movement's E.T2 section; Source: authors

We followed the same methodology of the comparative studies with the sonorities' amplitude values to investigate the pitches data. We performed a total of 3360 tests with pitch values for each instrument (840 for each) and grouped those with conclusive results by section type, for further analysis. 
A quantitative study of pitch registers in string quartets opus 17 , by Joseph Haydn

We organized the conclusive test results in pairs in Table 11, counting the number of movements in which the pitch values of each instrument in one section are lower or higher than that of the other.

\begin{tabular}{llllrr} 
& Section 1 & Section 2 & Attribute & Less & Greater \\
\hline 1 & E.T1 & E.T2 & Violin I pitches & 8 & 3 \\
2 & R.T1 & R.T2 & Violin I pitches & 9 & 4 \\
3 & E.T1 & R.T1 & Violin I pitches & 5 & 3 \\
4 & E.Tr & R.Tr & Violin I pitches & 1 & 3 \\
5 & E.T2 & R.T2 & Violin I pitches & 7 & 5 \\
6 & E.CT & R.CT & Violin I pitches & 5 & 5 \\
7 & E.T1 & E.Tr & Violin I pitches & 9 & 3 \\
8 & E.Tr & E.T2 & Violin I pitches & 8 & 3 \\
9 & E.T2 & E.CT & Violin I pitches & 2 & 11 \\
10 & E.CT & D & Violin I pitches & 10 & 2 \\
11 & D & R.T1 & Violin I pitches & 4 & 9 \\
12 & R.T1 & R.Tr & Violin I pitches & 3 & 1 \\
13 & R.Tr & R.T2 & Violin I pitches & 3 & 1 \\
14 & R.T2 & R.CT & Violin I pitches & 3 & 9 \\
15 & E.T1 & E.T2 & Violin II pitches & 5 & 7 \\
16 & R.T1 & R.T2 & Violin II pitches & 5 & 4 \\
17 & E.T1 & R.T1 & Violin II pitches & 3 & 4 \\
18 & E.Tr & R.Tr & Violin II pitches & 3 & 1 \\
19 & E.T2 & R.T2 & Violin II pitches & 7 & 5 \\
20 & E.CT & R.CT & Violin II pitches & 6 & 7 \\
21 & E.T1 & E.Tr & Violin II pitches & 4 & 5 \\
22 & E.Tr & E.T2 & Violin II pitches & 7 & 5 \\
23 & E.T2 & E.CT & Violin II pitches & 3 & 8 \\
24 & E.CT & D & Violin II pitches & 5 & 6 \\
25 & D & R.T1 & Violin II pitches & 4 & 9 \\
26 & R.T1 & R.Tr & Violin II pitches & 4 & 0 \\
27 & R.Tr & R.T2 & Violin II pitches & 2 & 1 \\
28 & R.T2 & R.CT & Violin II pitches & 5 & 6 \\
29 & E.T1 & E.T2 & Viola pitches & 7 & 5 \\
30 & R.T1 & R.T2 & Viola pitches & 5 & 7 \\
31 & E.T1 & R.T1 & Viola pitches & 4 & 4 \\
32 & E.Tr & R.Tr & Viola pitches & 3 & 0 \\
33 & E.T2 & R.T2 & Viola pitches & 4 & 8 \\
34 & E.CT & R.CT & Viola pitches & 6 & 6 \\
35 & E.T1 & E.Tr & Viola pitches & 7 & 4 \\
36 & E.Tr & E.T2 & Viola pitches & 8 & 3 \\
37 & E.T2 & E.CT & Viola pitches & 4 & 7 \\
38 & E.CT & D & Viola pitches & 8 & 5 \\
39 & D & R.T1 & Viola pitches & 4 & 6 \\
40 & R.T1 & R.Tr & Viola pitches & 3 & 1
\end{tabular}


MUSICA THEORICA Revista da Associação Brasileira de Teoria e Análise Musical 2020, v. 5, n. 1, p. 119-177 - Journal of the Brazilian Society for Music Theory and Analysis @ TeMA 2020 - ISSN 2525-5541

$\begin{array}{llllll}41 & \text { R.Tr } & \text { R.T2 } & \text { Viola pitches } & 1 & 2 \\ 42 & \text { R.T2 } & \text { R.CT } & \text { Viola pitches } & 3 & 4 \\ 43 & \text { E.T1 } & \text { E.T2 } & \text { Violoncello pitches } & 4 & 6 \\ 44 & \text { R.T1 } & \text { R.T2 } & \text { Violoncello pitches } & 4 & 8 \\ 45 & \text { E.T1 } & \text { R.T1 } & \text { Violoncello pitches } & 4 & 5 \\ 46 & \text { E.Tr } & \text { R.Tr } & \text { Violoncello pitches } & 3 & 0 \\ 47 & \text { E.T2 } & \text { R.T2 } & \text { Violoncello pitches } & 4 & 8 \\ 48 & \text { E.CT } & \text { R.CT } & \text { Violoncello pitches } & 3 & 8 \\ 49 & \text { E.T1 } & \text { E.Tr } & \text { Violoncello pitches } & 5 & 5 \\ 50 & \text { E.Tr } & \text { E.T2 } & \text { Violoncello pitches } & 4 & 4 \\ 51 & \text { E.T2 } & \text { E.CT } & \text { Violoncello pitches } & 5 & 5 \\ 52 & \text { E.CT } & \text { D } & \text { Violoncello pitches } & 6 & 5 \\ 53 & \text { D } & \text { R.T1 } & \text { Violoncello pitches } & 5 & 3 \\ 54 & \text { R.T1 } & \text { R.Tr } & \text { Violoncello pitches } & 3 & 1 \\ 55 & \text { R.Tr } & \text { R.T2 } & \text { Violoncello pitches } & 1 & 3 \\ 56 & \text { R.T2 } & \text { R.CT } & \text { Violoncello pitches } & 5 & 5\end{array}$

Table 11: Number of movements in which there is evidence in comparing the instruments' pitch values in the sections; Source: authors

We have chosen the cases with the most impressive imbalance in the number of movements for further study. In the pairs of section types E.T2 and E.CT, and E.CT and Development (rows 9 and 10 of Table 11), the section E.CT has higher values in the violin section than the adjacent ones in four movements (two compared to E.T2, compared to Development).

The first violin's part is markedly high-pitched in the op17n5-01 movement's E.CT section (Ex. 17). Comparative tests between this section and all others of the same type reveal its pitches as the highest. This fact helps to understand why this section pitches are higher than those of E.T2 and of the Development sections of this movement. 

in string quartets opus 17 , by Joseph Haydn
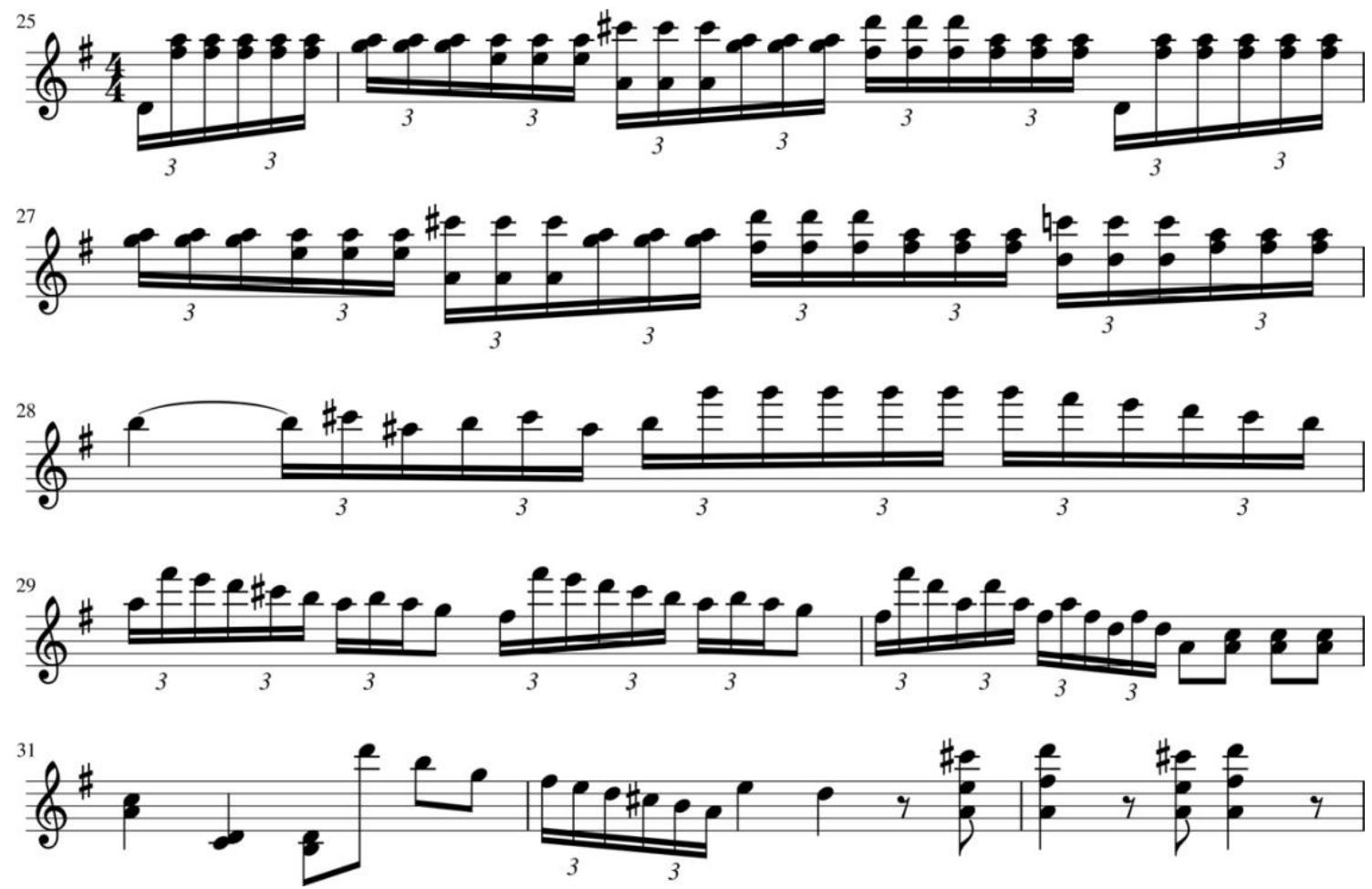

Example 17: First violin part of the op17n5-01 movement's E.CT section (m. 25-33); Source: authors

There are two cases where the low-pitch predominance in the first violin influences pitch comparisons involving the E.CT sections. The first, between op17n3-04 movement's E.CT and development sections, and the second, between op17n6-01 movement's E.CT and E.T2 sections (Ex. 18).
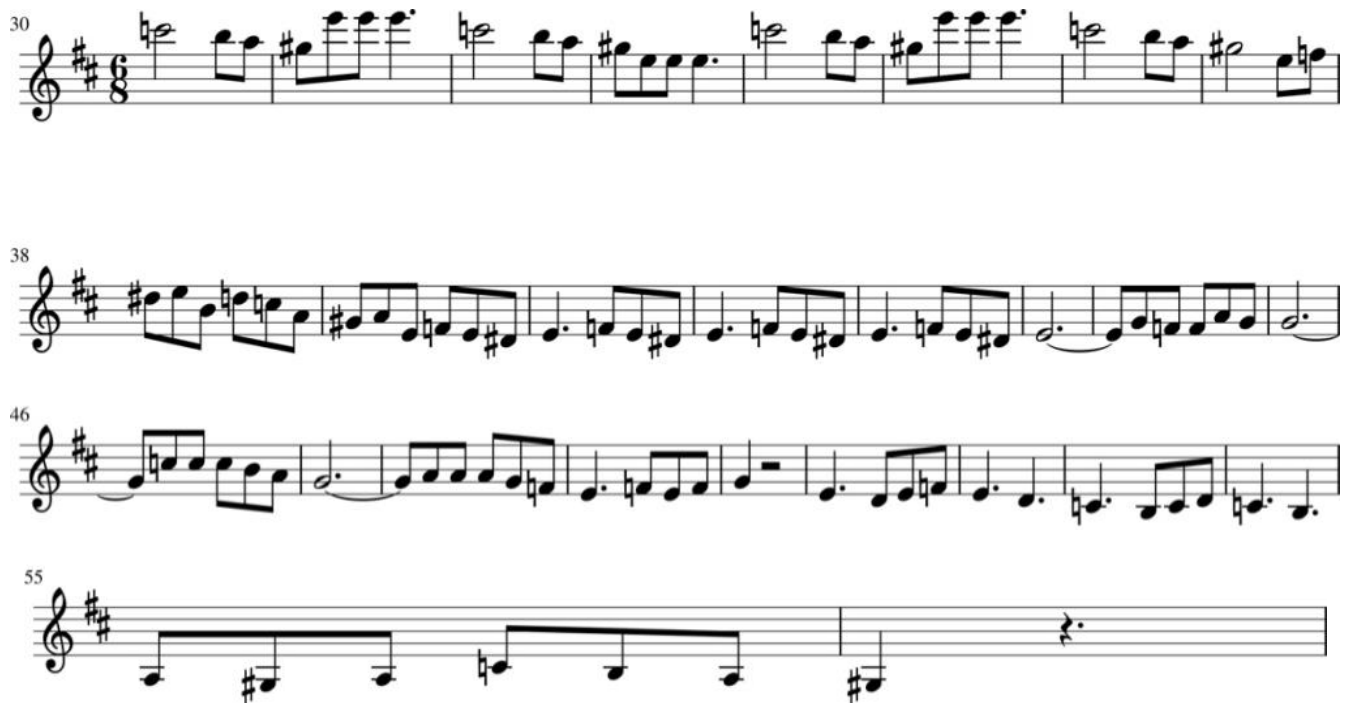

Example 18: First violin part of the op17n6-01 movement's E.T2 section (m. 30-56); Source: authors 
MUSICA THEORICA Revista da Associação Brasileira de Teoria e Análise Musical 2020,

v. 5, n. 1, p. 119-177 - Journal of the Brazilian Society for Music

\subsection{Contour similarity}

We carried out studies of similarity of contours of vertical sonorities' amplitude values and instruments' pitches. For each study, we combined sectionobjects pairs belonging to the same movement -in a 1-1 comparison procedure (see section 3.2) - we obtained the contours of the data in both objects of each pair, and we calculated the similarity index between these contour pairs. We performed a total of 4200 contour comparisons -840 of contours of sonorities' amplitude and 840 of pitch contours of each of the instruments.

We have grouped these section-object pairs' similarity indices in two ways: by movement and by section type. Thus, we obtained 13 object pairs groups, referring to the movements, and 10, referring to the section types. Fig. 10 shows the similarity values distributions of the 13 movements groups, and Fig. 11 , of the 10 section types groups.

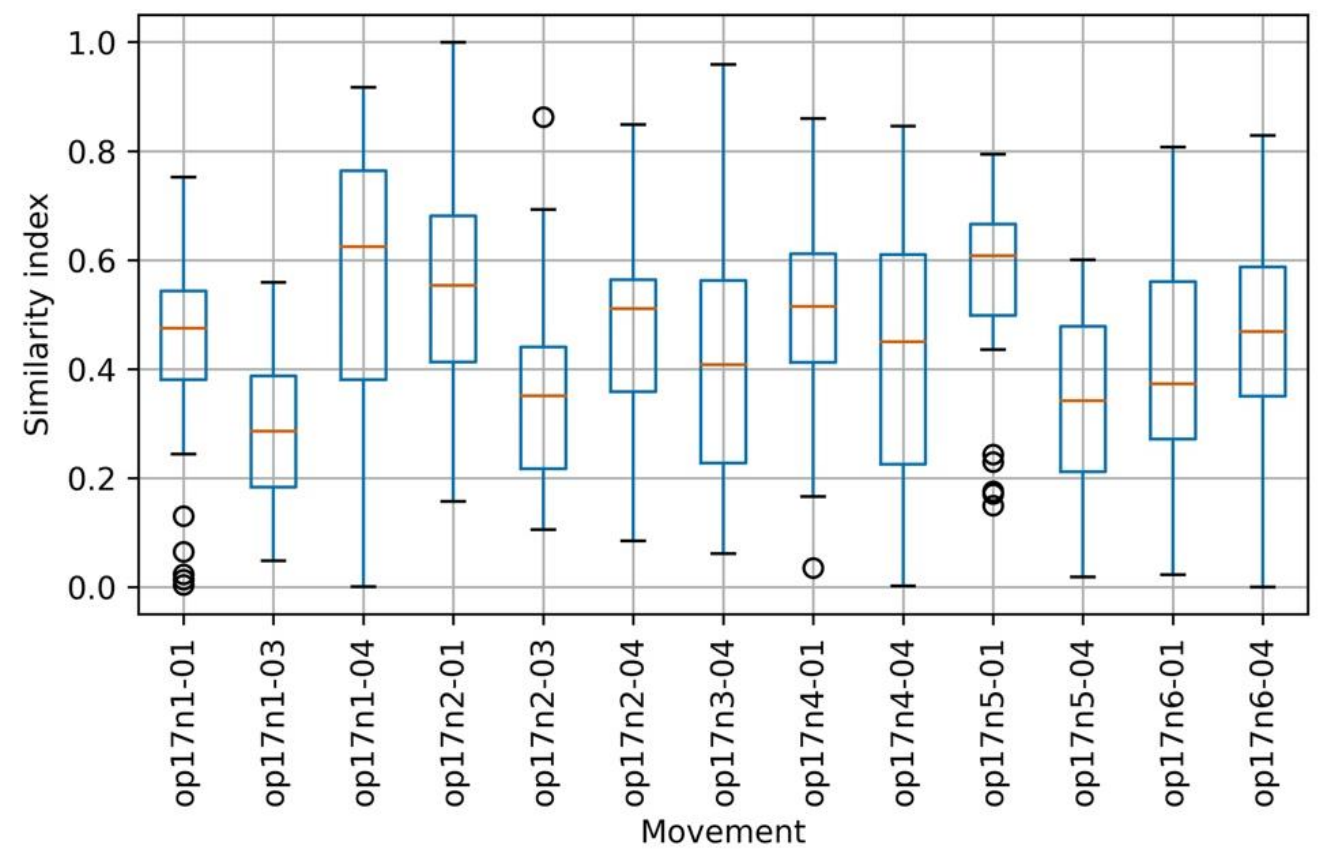

Figure 10: Distributions of similarity indices among the contours of sonorities' amplitude of the same movement sections; Source: authors 
A quantitative study of pitch registers in string quartets opus 17 , by Joseph Haydn

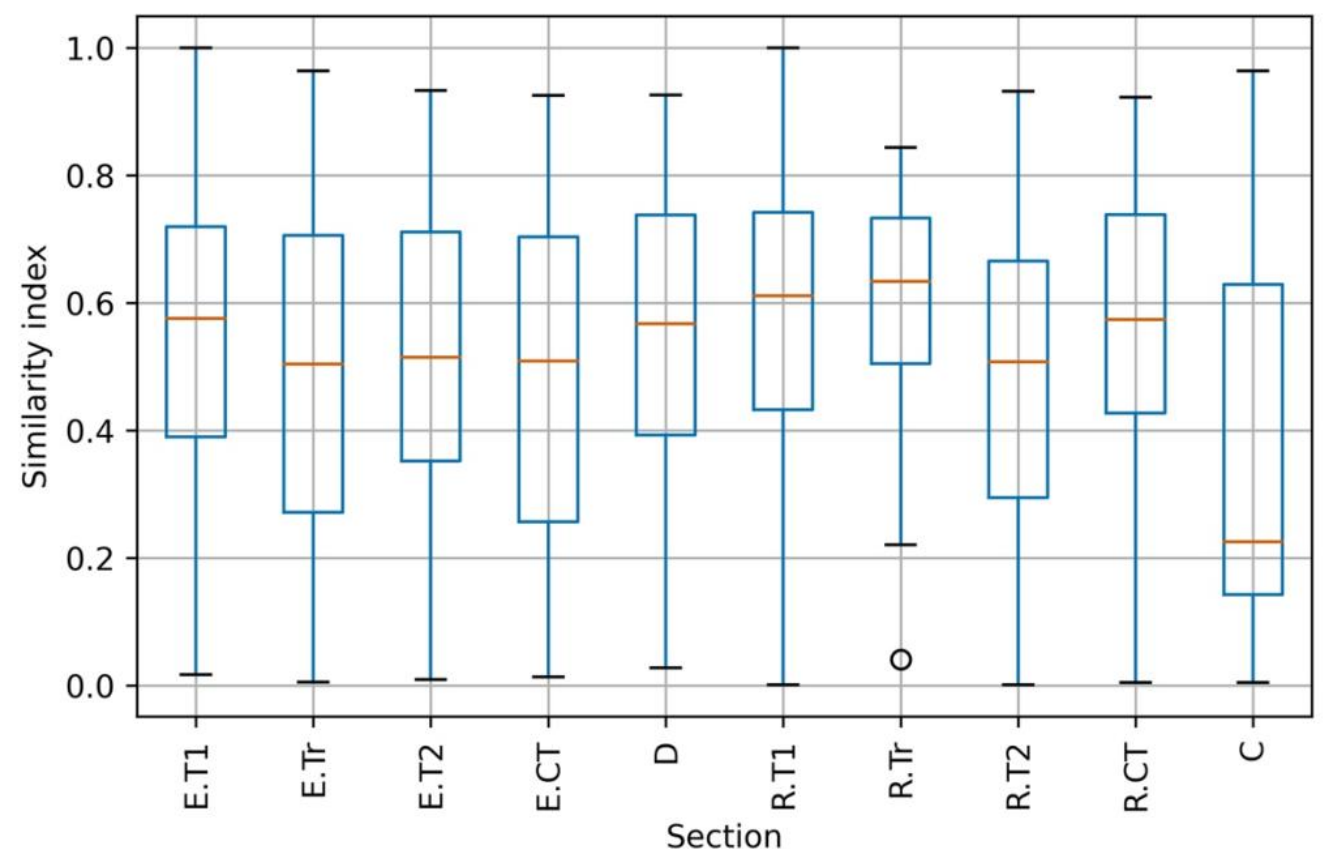

Figure 11: Distributions of similarity indices between the contours of sonorities' amplitude of the same type sections; Source: authors

The distribution's non-normality and the overlapping values makes it difficult to perceive higher/lower value relationships between the distributions in these graphics, especially in the groupings by section type (Fig. 11), so we performed exploratory hypothesis tests.

In both studies, by movement and by section type, we have conducted tests for each group and its complement. Table 12 shows the results of the range of amplitude contours and Table 13 for the pitch contours. Both tables contain conclusive tests only.

\begin{tabular}{lllll}
\hline & Sample 1 & Sample 2 & Attribute & Value \\
\hline 1 & op17n1-03 movement & Others & Amplitude & Less similar \\
2 & op17n1-04 movement & Others & Amplitude & More similar \\
3 & op17n2-01 movement & Others & Amplitude & More similar \\
4 & op17n2-03 movement & Others & Amplitude & Less similar \\
5 & op17n5-01 movement & Others & Amplitude & More similar \\
6 & op17n5-04 movement & Others & Amplitude & Less similar \\
7 & E.Tr section & Others & Amplitude & Less similar \\
8 & D section & Others & Amplitude & More similar
\end{tabular}


MUSICA THEORICA Revista da Associação Brasileira de Teoria e Análise Musical 2020, v. 5, n. 1, p. 119-177 - Journal of the Brazilian Society for Music

Table 12: Hypotheses with conclusive data regarding movements and sections amplitude contour similarity. Each row represents a hypothesis regarding the contour of the attribute given in samples 1 and 2; Source: authors

\begin{tabular}{lllll}
\hline & Sample 1 & Sample 2 & Attribute & Value \\
\hline 1 & op17n1-01 movement & Others & Violin I pitches & More similar \\
2 & op17n1-03 movement & Others & Violin I pitches & Less similar \\
3 & op17n1-04 movement & Others & Violin I pitches & More similar \\
4 & op17n4-01 movement & Others & Violin I pitches & More similar \\
5 & op17n5-04 movement & Others & Violin I pitches & Less similar \\
6 & op17n1-03 movement & Others & Violin II pitches & Less similar \\
7 & op17n1-04 movement & Others & Violin II pitches & More similar \\
8 & op17n2-01 movement & Others & Violin II pitches & Less similar \\
9 & op17n2-03 movement & Others & Violin II pitches & Less similar \\
10 & op17n4-04 movement & Others & Violin II pitches & Less similar \\
11 & op17n6-01 movement & Others & Violin II pitches & More similar \\
12 & op17n6-04 movement & Others & Violin II pitches & More similar \\
13 & op17n1-03 movement & Others & Viola pitches & Less similar \\
14 & op17n1-04 movement & Others & Viola pitches & More similar \\
15 & op17n2-01 movement & Others & Viola pitches & Less similar \\
16 & op17n2-03 movement & Others & Viola pitches & Less similar \\
17 & op17n3-04 movement & Others & Viola pitches & More similar \\
18 & op17n1-04 movement & Others & Violoncello pitches & More similar \\
19 & op17n2-04 movement & Others & Violoncello pitches & More similar \\
20 & op17n5-04 movement & Others & Violoncello pitches & Less similar \\
21 & D section & Others & Violin I pitches & Less similar \\
22 & R.T1 section & Others & Violin II pitches & More similar \\
23 & C section & Others & Violin II pitches & Less similar \\
24 & E.CT section & Others & Violoncello pitches & Less similar \\
\hline & & & & \\
\hline
\end{tabular}

Table 13: Hypotheses with conclusive data regarding movements and sections pitch contour similarity. Each row represents a hypothesis regarding the contour of the attribute given in samples 1 and 2; Source: authors

For each row in these tables, we found evidence to affirm that the sample 1 values are higher (or lower) than its complement. For example, we can interpret the second line of Table 12 as "at the 1\% significance level, there is evidence that the similarity of amplitude contours between op17n1-04 movement sections is higher than the similarity between the sections of the others corpus' movements".

We did not find relevant data in the study of the similarity between contours in the grouping by movement. However, the "by section type" 
A quantitative study of pitch registers in string quartets opus 17, by Joseph Haydn

grouping reveals valuable information about the development section: the amplitude contour similarity is higher between the development section and its complement, and the pitch contour similarity is lower between this section type and its complement.

These tests results allow us to conclude:

The behavior of the vertical sonorities' amplitude in the development sections tends to infer some pattern, due to the high-value similarity between their contours.

The development section has the highest melodic diversity, as it is the only one in which there are lower contour similarity index values on the pitches of all instruments.

The exposition's concluding theme section has less melodic diversity in the violoncello than in the other instruments. One hypothesis for this aspect is that the ending character interferes with the bass line that the violoncello makes.

\section{Intra-section comparisons}

Here, we present comparative studies between the data in each section.

\subsection{Contour profiles of the sonorities' amplitudes}

The study of the vertical sonorities' amplitudes contours of the sectionobjects revealed a tendency to avoid the value peak at the beginnings and ends of the sections. The amplitude peak does not occur at the sections beginnings in $94 \%$ of cases, ending in $97 \%$, and beginning nor ending in $91 \%$. In the same way, there is a small tendency to avoid the lower amplitude value at the beginning and end - in $76 \%$ of cases there is no occurrence at the beginning, in $68 \%$, there is no occurrence at the end, and in $50 \%$, there is no occurrence at the beginning nor the end. In a way, these data corroborate the expectation that the apexes of musical sections tend to occur in intermediate positions of the temporal space.

We reduced the amplitude contours and observed that the $<120>,<021>$ and $<10302>$ profiles are very usual, equivalent to $51 \%$ of the sections (see Fig. 12). The six sections in which the sonorities' amplitude starts at its apex have the reduced contour $<201>$. It consists of three sections with a conclusive theme of the exposition (n2-01, n3-04, n6-04 movements), two of a second-theme-zone (in n1-03 movement), and one of retransition (n2-01 movement). 
MUSICA THEORICA Revista da Associação Brasileira de Teoria e Análise Musical 2020, v. 5, n. 1, p. 119-177 - Journal of the Brazilian Society for Music

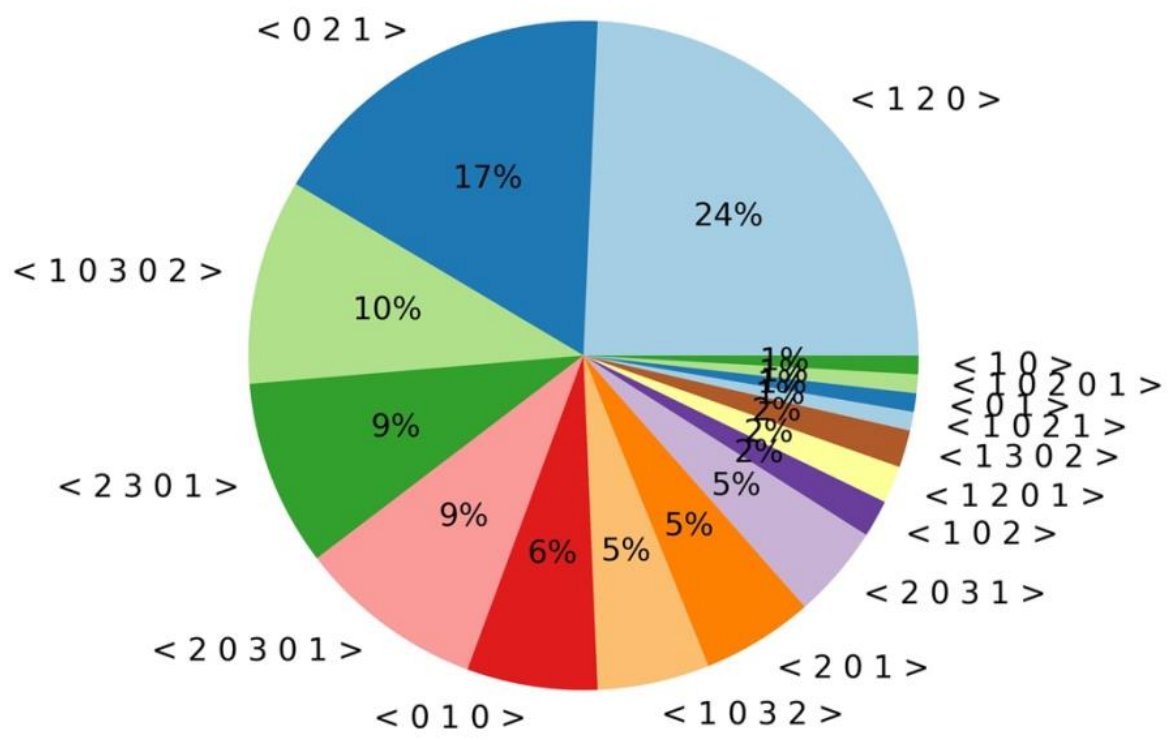

Figure 12: Reduced contours of the sections' vertical sonorities' amplitudes; Source: the author

The musical context analysis of the op17n2-01 movement's retransition shows the reason for its lowest amplitude value. It occurs due to the progressive increase in the violoncello pitches until the final moment. At the end of the section, the higher-pitch fragment on the first violin leads to a slight increase in amplitude (see amplitude values in Fig. 13).

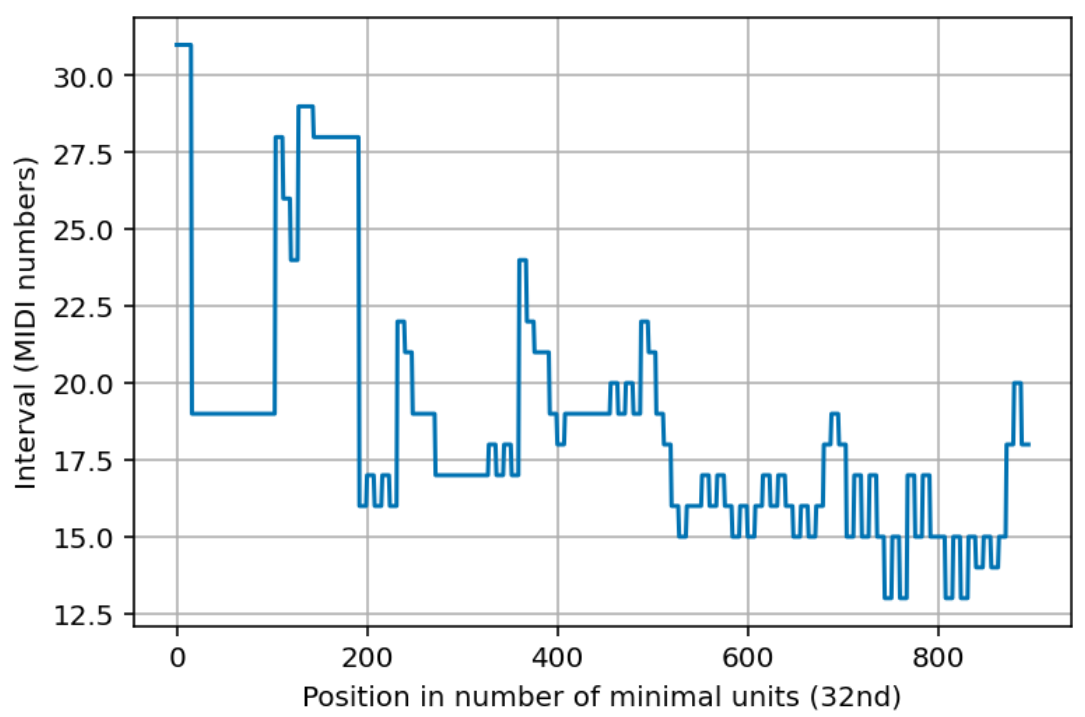

Figure 13: Vertical sonorities' amplitude values of the op17n2-01 movement's retransition section; Source: authors 
A quantitative study of pitch registers in string quartets opus 17 , by Joseph

Haydn

The musical context analysis in the op17n1-03 movement's E.T2 section confirms the coincidence between extreme amplitude values and segmentation points. This section consists of two parts, two sentences each. In this section, the lowest amplitude value occurs at the end of the third sentence, in a brief rest on the first violin part, before the final section sentence (see the identified point in Ex. 19).
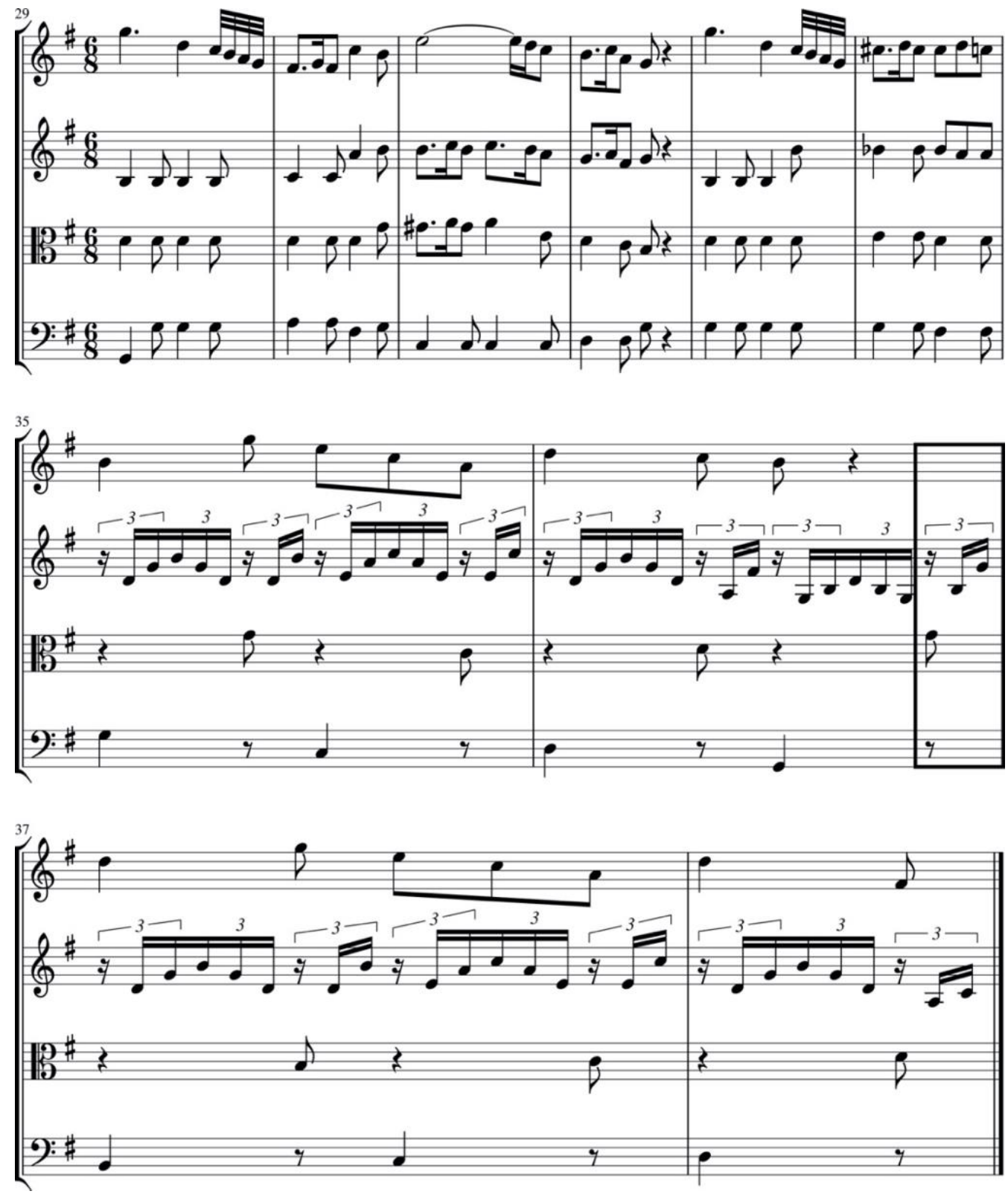

Example 19: Op17n1-03 movement's E.T2 section (m. 29-38); Source: authors

Another interesting case is the seven sections with reduced contours $<01$ $0>$. All of these sections begin and end with a solo instrument. 
MUSICA THEORICA Revista da Associação Brasileira de Teoria e Análise Musical 2020,

The study of the equivalent classes of the reduced contours reveals that $49 \%$ of the sections have an amplitude contour belonging to the class $<021>$ and that $82 \%$ have contours belonging to only three classes, $<021>,<10302>$ and $<1$ 03 2> (Fig. 14). We can see, therefore, a global pattern of behavior of the amplitude values in the analyzed sections.

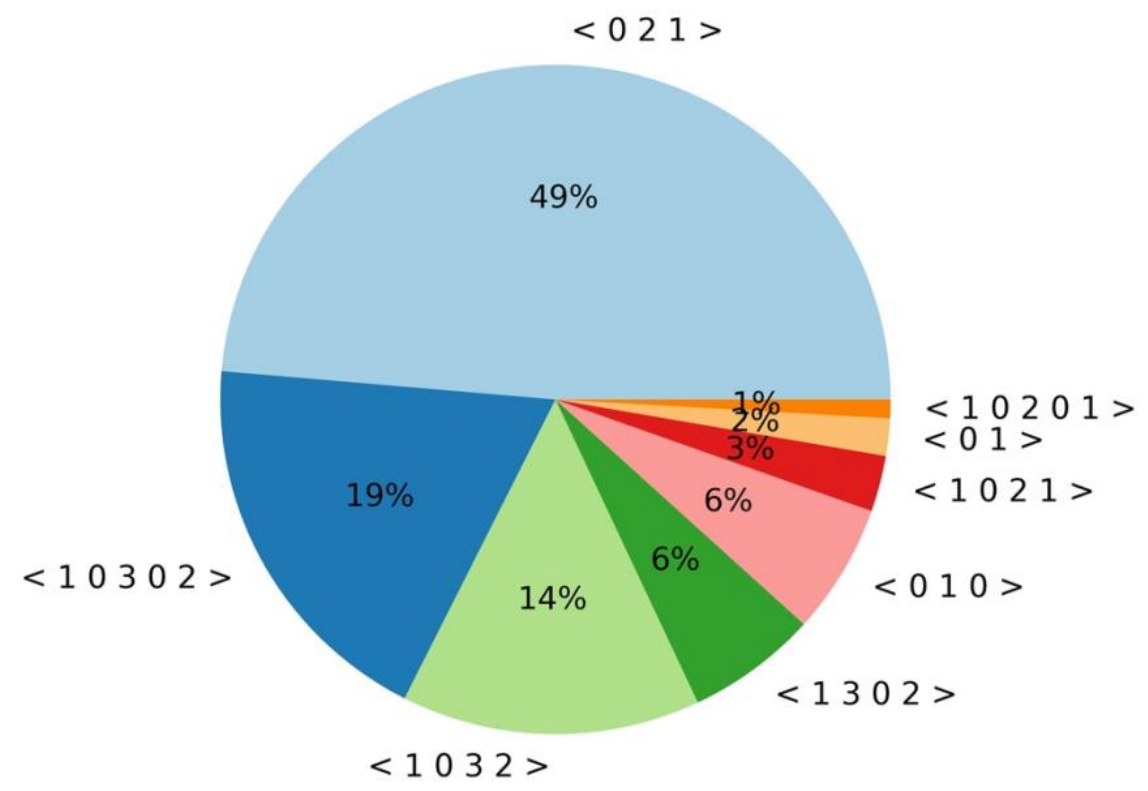

Figure 14: Reduced contour classes of the sections' vertical sonorities' amplitudes; Source: the author.

\subsection{Correlations between sonorities' amplitude values and instrument pitches}

We found correlations between vertical sonorities' amplitude values and instrument pitches. This correlation is positive between violins and viola pitches and amplitude values, and negative between violoncello pitches and amplitude values. This result is predictable since the amplitude values depend on the opposite pitch values in the first violin and the violoncello.

We have used two methodological approaches: to join the data of the section-objects belonging to the same movement and to consider the data of the section-objects separately. In the study of movement's data, we found evidence regarding the correlations between amplitude and first violin pitches, and amplitude and violoncello pitches in all movements. In the case of the second violin and viola, the result was not unanimous, as shown in Table 14. Only in the 
A quantitative study of pitch registers in string quartets opus 17, by Joseph Haydn

op17n5-04 movement, we did not find evidence of a correlation between amplitude data and violin 2 , with p-value 0.51 .

\begin{tabular}{llrr} 
& Data & Positive & Negative \\
Instrument & & & \\
\hline Violin I & Amplitude & 13 & 0 \\
Violin II & Amplitude & 11 & 1 \\
Viola & Amplitude & 9 & 4 \\
Violoncello & Amplitude & 0 & 13
\end{tabular}

Table 14: Number of movements with positive and negative correlations between sonorities' amplitude values and the instruments' pitches; Source: authors

The study results with data from individual sections were similar to those from movements. Table 15 shows that 97 sections have a positive correlation between the amplitude and first violin pitches, and 98, a negative one between amplitude and violoncello pitches. In the internal voices, it is not possible to observe a predominance of positive or negative correlation. In 62 studies, we found no evidence to confirm any correlation.

\begin{tabular}{llrr} 
& Data & Positive & Negative \\
Instrument & & & \\
\hline Violin I & Amplitude & 97 & 5 \\
Violin II & Amplitude & 45 & 38 \\
Viola & Amplitude & 49 & 39 \\
Violoncello & Amplitude & 5 & 98 \\
\hline
\end{tabular}

Table 15: Number of sections with positive and negative correlations between the vertical sonorities' amplitude values and instrument pitches; Source: authors

The difference in results between the movement's and section type's data is due to the observable sensitivity of the individual sections' data. The latter is more sensitive to particularities of textures and composition processes than the former.

We performed a musical context analysis in the sections in which the correlation between amplitude and pitches of the violoncello was positive. We found a similarity in the reasons that lead to this result in the op17n6-01-E.T2, op17n4-04-E.T2, and op17n4-01-E.Tr sections. In these cases, there is the first segment with a tendency to pedal notes and a second, with the direction of the 
violoncello notes towards the lower register accompanied by a similar movement of the first violin notes. This movement in the same direction maintains the amplitude when the violoncello is in the low register, making the segment with the pedal the stretch with the highest amplitude value (see transition section of the movement exposition op17n4-01 in Ex. 4, in section 4.2.)

\section{Discussion}

We have chosen four aspects of this study to expand the discussion.

\subsection{The singularity of the second theme and development sections}

In this study, we noted a peculiarity in the second theme and development sections. As seen in section 5.1, both the instrumental pitches and vertical sonorities' amplitude values of these two sections are higher than the other sections ones. As seen in section 5.2, the amplitude and first violin pitch values ratify this aspect. These data corroborate Malcolm Miller's argument (2006) about the sonata form principle reinforcement resulting from the high-pitch register in the second theme, in comparison to the first theme and transition, in the analysis of the op. 59 by Beethoven.

For example, in the op17n4-01 movement, the violin's greatest ambitus occurs in the E.T2 section (Fig. 15 and Ex. 20), where 75\% of the pitches are above F5.

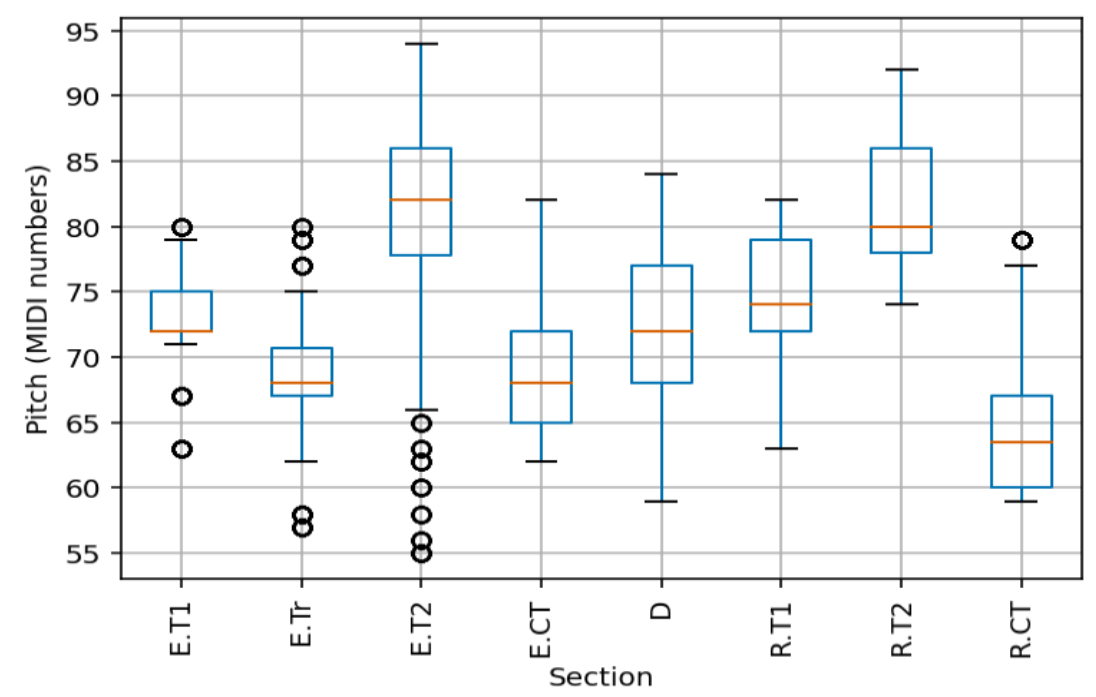

Figure 15: Distribution of first violin's pitches in the op17n4-01 movement, with emphasis on the second theme's values; Source: authors 
A quantitative study of pitch registers in string quartets opus 17, by Joseph Haydn
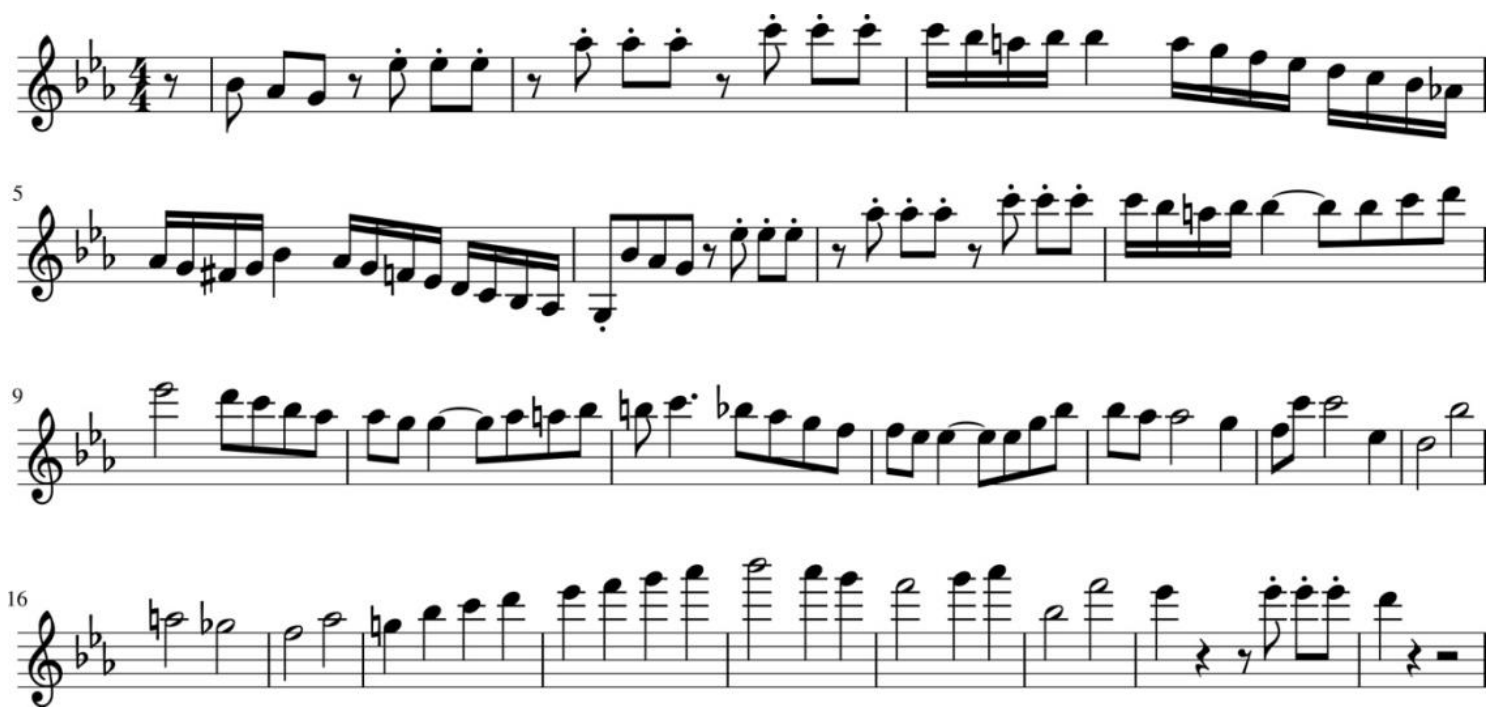

Example 20: First violin's part in the op17n4-01 movement's E.T2 section (m. 1-24); Source: authors

The study of the instrumental register corroborates the contrast between the first and second themes and suggests higher brightness and difficulty on execution in the second theme and development sections. Additionally, the violin's part has higher diversity in terms of melodic contour in the development section, than in the others.

\subsection{Outliers in reinforcing musical strategies}

The atypical values of note pitches and vertical sonorities' amplitude occur in several musical situations, as categorized in section 4.2. Thus, the outliers study is relevant because it can reveal musically significant points.

Our segmentation of outliers into two parts - movement and sectionallows switching between global and local levels. The op17n1-04 movement's first theme section is a good illustration of this issue. Regarding the vertical sonorities' amplitude, this section is noteworthy because its amplitude values are lower than any other section in the same movement and coincide with the form segmentation.

In this section, the amplitude values are low due to the predominance of the two voices thirds texture. Although this texture is frequent in other sections, the use of all the quartet instruments predominates in this section's movement. The only points with higher amplitude values are outliers and occur at the phrases ending. There is a predominance of low amplitude values and strategic 
preservation of the amplitude extremes to support the apex and the section's formal segmentation.

Another relevant issue is that these high amplitude values, between 20 and 36 semitones, are extreme only when we have compared them to this section's values. These values are not outliers when compared with the entire movement's amplitude values. In the scope of this movement as a whole, only higher amplitude values, between 39 and 43 semitones, are considered outliers. This section's outliers are very subtle, at an intermediate level, unmatched by the movement's amplitude's extremes. This fact demonstrates the extremes' analysis subtlety o and the need to study the sections' data separately.

This formal segmentation is easily noticeable by the symmetry of the graph of the section's amplitude values (Fig. 16).

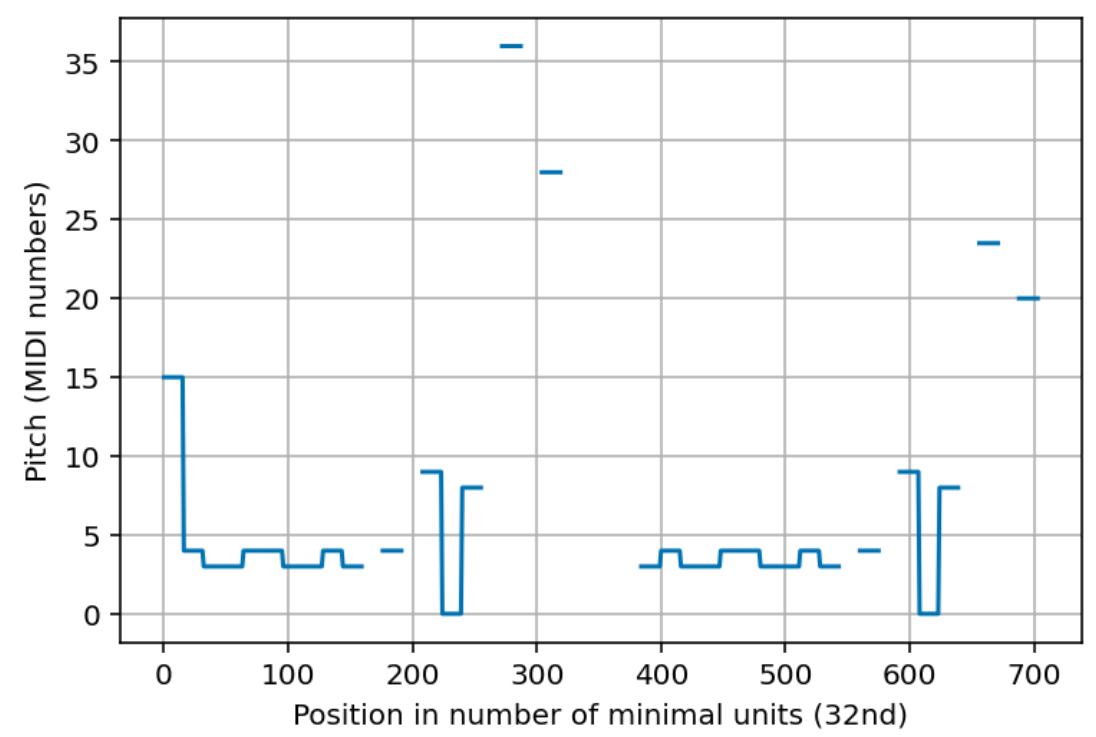

Figure 16: Amplitude values of the first theme section of the op17n1-04 movement's exposition; Source: authors

\subsection{Tendency towards contour patterns}

The results of the study of the contours in the development sections revealed antagonistic information. On the one hand, there is a tendency to differentiate the pitch contours of instrumental parts between sections of this type. Considering that the development section of each musical work in Forma Sonata is unique, without a formal design pattern (Green 1979, p. 195), this differentiation corroborates expectations. 
A quantitative study of pitch registers in string quartets opus 17 , by Joseph Haydn

On the other hand, regarding amplitude's contour comparison among sections of the same type, there is a visible tendency towards similarity in development sections, when compared to others. This fact leads to a certain method in the amplitude organization in this type of section. We found that 9 in 13 sections have amplitude contours reducible to only three forms: $\langle 120>,<01$ $0>$ and $<20301>$ (see Fig. 17).

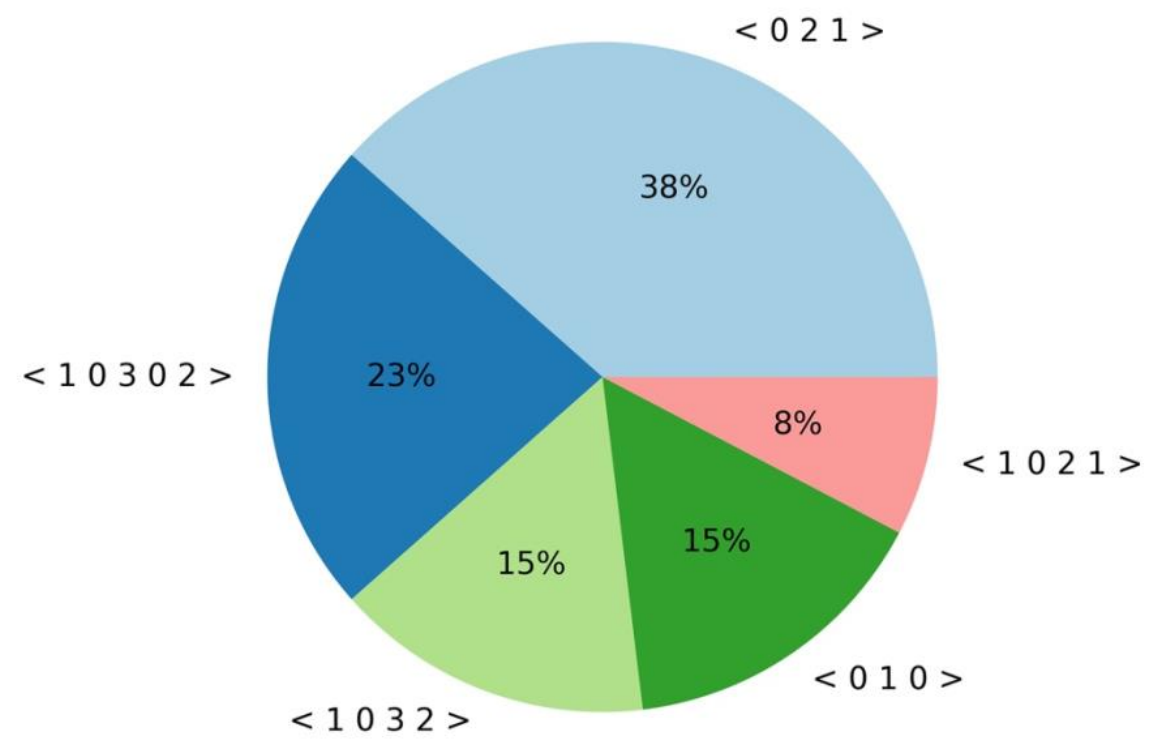

Figure 17: Contour reductions of the development sections; Source: authors

It is good to indicate that only the development section gathered enough evidence for conclusions in all the tests we did, with contours of sonorities' amplitudes and pitches of each instrument.

\subsection{Amplitude of the vertical sonorities and the instrument's pitches}

Although the vertical sonorities' amplitude coincides with several relevant musical structures (see sections 4.1, 5.1, and 5.2), we noticed some limitations in this study. Low amplitude outliers typically converge to brief solo passages with no major musical significance (see section 4.1). Also, the impact of texture and composition techniques presses down on amplitude values (see section 5.2).

The results of the studies regarding the instrument pitches were much more accurate in coincidence with relevant musical issues. Thus, individual pitch 
MUSICA THEORICA Revista da Associação Brasileira de Teoria e Análise Musical 2020,

studies are more reliable to understand the role of registers in the study of a musical piece.

\section{Conclusion}

In this paper, it is possible to observe that the values of the instruments' pitches and the vertical sonorities' amplitudes corroborate expectations of the Sonata Form when analyzed comparatively between different section types. As seen in section 7.1, the values of instrumental pitches in the second theme and development sections are markedly higher than those in other sections.

Also, we have found that the extreme values of these parameters reinforce relevant musical aspects, such as the phrase endings, phrase segments, small melodic local apexes, and changes in texture and harmonic rhythm.

The study of pitch registers supported by the Contour Theory revealed behavior patterns. Additional developments can also occur with the support of many other theories, such as Schenkerian analysis and partitional analysis of texture (see Gentil-Nunes 2013).

We have realized that the use of statistical techniques allows the collecting of various relevant musical information about the pitch register, with a low tendency to bias. Other studies, like cluster analysis, may reveal further points.

In the case of computer-aided analysis, the statistical techniques allow to identify repertoires features in large corpora in a short time. Such a possibility is impressive for feeding the research and leading to new insights. The present study, as a prototype, was restricted to a very concise corpus. A possible development is to use such techniques to verify the registers' behavior among pieces from different moments of a same composer life, of composers from a same period, or even composers from different periods. This type of study may expand the knowledge about the characteristics of the repertoire.

\section{Acknowledgments}

This article is part of the "Quantitative research of the String Quartets by Haydn, Mozart, and Beethoven" project, supported by CNPQ and Fapesb.

We thank Dr. Pedro Kroger and Dr. Ricardo Bordini for all the research suggestions, and André Matera, for the score encodings support. 
A quantitative study of pitch registers in string quartets opus 17, by Joseph Haydn

\section{References}

1. Adrian, Jack. 1991. "The Function of the Apparent Tonic at the Beginning of Development Sections." Intégral, v. 5, p. 1-53.

2. Antonicek, Theophil, Derek Beales, Leon Botstein, Rudolf Klein, and Harald Goertz. 2001. “Vienna.” Grove Music Online. Oxford University Press.

3. Bartha, Dénes. 1969. "Thematic Profile and Character in the Quartet-Finales of Joseph Haydn (A Contribution to the Micro-Analysis of Thematic Structure)." Studia Musicologica Academiae Scientiarum Hungaricae, v. 11, n. 1/4, p. 35-62.

4. Bellmann, Héctor G. 2011. "Categorization of Tonal Music Style: A Quantitative Investigation." Ph.D. Dissertation. Griffith University.

5. Beran, Jan. 2004. Statistics in Musicology. Boca Raton, Fla: Chapman \& Hall/CRC.

6. Bernard, Jonathan W. 1981. "Pitch/Register in the Music of Edgard Varèse." Music Theory Spectrum, v. 3, p. 1-25.

7. Birson, Adem Merter. 2014. "The Use of Minor Mode and Playing With Sonority in the Expositions of Haydn's String Quartets, Opp. 9 and 17." Haydn: Online Journal of the Haydn Society of North America, v. 4, n. 1, p. 1-30.

8. Birson, Adem Merter. 2015. "Haydn's Dramatic Dissonances: Chromaticism and Formal Process in His String Quartets, Opp. 9 and 17." Ph.D. Dissertation. Cornell University.

9. Drabkin, William. 2000. A Reader's Guide to Haydn's Early String Quartets. Westport, CT: Greenwood Press.

10. Friedmann, Michael L. 1985. "A Methodology for the Discussion of Contour: Its Application to Schoenberg's Music." Journal of Music Theory, v. 29, n. 2, p. 223-248.

11. Gauldin, Robert. 1997. Harmonic Practice in Tonal Music. New York, NY: W.W. Norton and Company.

12. Gentil-Nunes, Pauxy. 2009. "Análise Particional: Uma Mediação Entre Composição Musical e a Teoria Das Partições." Ph.D. Dissertation. Universidade Federal do Rio de Janeiro.

13. Gentil-Nunes, Pauxy. 2013. "Partitional Analysis and Rhythmic Partitioning: Mediations Between Rhythm and Texture." In 13th International Music Theory Conference, pp. 44-51. Vilnius, Lituania. 
MUSICA THEORICA Revista da Associação Brasileira de Teoria e Análise Musical 2020, v. 5, n. 1, p. 119-177 - Journal of the Brazilian Society for Music

14. Grave, Floyd K. 1995. "Metrical Dissonance in Haydn." The Journal of Musicology, v. 13, n. 2, p. 168-202.

15. Grave, Floyd K., and Margaret Grave. 2006. The String Quartets of Joseph Haydn. New York, NY: Oxford University Press.

16. Green, Douglass M. 1979. Form in Tonal Music: An Introduction to Analysis. New York: Holt Rinehart and Winston.

17. Haydn, Joseph. 2000. String Quartets Op 17, Complete. Edited by Wilhelm Altmann. Mineola, NY: Dover Publications, Inc.

18. Hepokoski, James A., and Warren Darcy. 2006. Elements of Sonata Theory: Norms, Types, and Deformations in the Late-Eighteenth-Century Sonata. Oxford: Oxford University Press.

19. Huron, David. 1996. "The Melodic Arch in Western Folksongs." Computing in Musicology, v. 10, p. 3-23.

20. Huron, David, and Mathew Royal. 1996. "What is Melodic Accent? Converging Evidence from Musical Practice." Music Perception, v. 13, n. 4, p. 489-516.

21. Koechlin, Charles. n.d. Traité de l'Harmonie. Paris: Éditions Max Eschig.

22. Kohs, Ellis Bonoff. 1976. Musical Form: Studies in Analysis and Synthesis. Boston: Houghton Mifflin.

23. Kostka, Stefan M., Dorothy Payne, and Byron Almén. 2017. Tonal Harmony: With an Introduction to Post-Tonal Music. 8th ed. New York: McGraw-Hill Education.

24. Kranenburg, Peter Van, and Eric Backer. 2004. "Musical Style Recognition - a Quantitative Approach." In Proceedings of the Conference on Interdisciplinary Musicology, p. 1-10.

25. Larson, Steve. 2003. "Recapitulation Recomposition in the Sonata-Form First Movements of Haydn's String Quartets: Style Change and Compositional Technique." Music Analysis, v. 22, n. 1/2, p. 139-177.

26. Lockwood, Lewis. 1992. Beethoven: Studies in the Creative Process. Cambridge, MA; London: Harvard University Press.

27. MacKay, James S. 2013. "Franz Joseph Haydn and the Five-Octave Classical Keyboard: Registral Extremes, Formal Emphases, and Tonal Strategies." Canadian University Music Review, v. 23, n. 1-2, p. 126-144. 
A quantitative study of pitch registers in string quartets opus 17 , by Joseph Haydn

28. MacKay, James S. 2014. "Sonata Form Experimentation in Joseph Haydn's String Quartets, Opus 17." Haydn: Online Journal of the Haydn Society of North America, v. 4, n. 1, p. 1-31.

29. Marsden, Alan. 2015. "Music Analysis by Computer: Ontology and Epistemology." In Computational Music Analysis, edited by David Meredith, p. 3-28. Aalborg, Denmark: Springer.

30. Marvin, Elizabeth West, and Paul A. Laprade. 1987. "Relating Musical Contours: Extensions of a Theory for Contour." Journal of Music Theory, v. 31, n. 2, p. 225-267.

31. Miller, Malcolm. 2006. "Peak Experience High Register and Structure in the 'Razumovsky' Quartets, Op. 59." In The String Quartets of Beethoven, edited by William Kinderman. Urbana and Chicago: University of Illinois Press.

32. Morris, Robert Daniel. 1987. Composition with Pitch-Classes: A Theory of Compositional Design. Yale University Press.

33. Morris, Robert Daniel. 1993. "New Directions in the Theory and Analysis of Musical Contour." Music Theory Spectrum, v. 15, n. 2, p. 205-228.

34. November, Nancy. 2007. “Register in Haydn's String Quartets: Four Case Studies." Music Analysis, v. 26, n. 3, p. 289-322.

35. November, Nancy. 2008. “Instrumental Arias or Sonic Tableaux: 'Voice' in Haydn's String Quartets Opp. 9 and 17." Music and Letters, v. 89, n. 3, p. 346372.

36. Oster, Ernst. 1961. "Register and the Large-Scale Connection." Journal of Music Theory, v. 5, n. 1, p. 54.

37. Rosen, Charles. 1997. The Classical Style: Haydn, Mozart, Beethoven. Expanded e. New York, NY: W. W. Norton \& Company.

38. Rosen, Charles. 2001. Critical Entertainments: Music Old and New. Cambridge, MA: Harvard University Press.

39. Rumph, Stephen. 2014. “What Beethoven Learned from K464." Eighteenth Century Music, v. 11, n. 1, p. 55-77.

40. Sampaio, Marcos da Silva. 2012. "A Teoria de Relações de Contornos Musicais: Inconsistências, Soluções e Ferramentas." Ph.D. Dissertation. Universidade Federal da Bahia.

41. Sampaio, Marcos da Silva. 2018. "Contour Similarity Algorithms." MusMat Brazilian Journal of Music and Mathematics, v. 2, n. 2, p. 58-78. 
MUSICA THEORICA Revista da Associação Brasileira de Teoria e Análise Musical 2020, v. 5, n. 1, p. 119-177 - Journal of the Brazilian Society for Music

42. Sampaio, Marcos da Silva, and Pedro Kroger. 2016. "Contour Algorithms Review." MusMat - Brazilian Journal of Music and Mathematics, v. 1, n. 1, p. 7285.

43. Schmuckler, Mark A. 2010. "Melodic Contour Similarity Using Folk Melodies." Music Perception, v. 28, n. 2, p. 169-194.

44. Schubert, Peter, and Julie Cumming. 2015. "Another Lesson from Lassus: Using Computers to Analyse Counterpoint." Early Music, v. 43, n. 4, p. 577586.

45. Schultz, Rob D. 2009. "A Diachronic-Transformational Theory of Musical Contour Relations." Ph.D. Dissertation. University of Washington.

46. Schultz, Rob D. 2016. "Normalizing Musical Contour Theory." Journal of Music Theory, v. 60, n. 1, p. 23-50.

47. Sousa, Daniel Moreira de. 2015. “Perspectivas Para a Análise Textural a Partir Da Mediação Entre a Teoria Dos Contornos e a Análise Particional." Ph.D. Dissertation. Universidade Federal do Rio de Janeiro.

48. Triola, Mario F. 2013. Elementary Statistics. 10th ed. Boston: Pearson Addison Wesley.

49. Väisälä, Olli. 2009. “Bach's Inventions: Figuration, Register, Structure, and the 'Clear Way to Develop Inventions Properly.'” Music Theory Spectrum, v. 31, n. 1, p. 101-152.

50. Volk, Anja, Frans Wiering, and Peter van Kranenburg. 2011. “Unfolding the Potential of Computational Musicology." Proceedings of The13th International Conference on Informatics and Semiotics in Organisations (ICISO), p. 137-144.

51. Webster, James. 1975. “The Chronology of Haydn's String Quartets.” The Musical Quarterly, v. 61, n. 1, p. 17-46.

52. Webster, James. 1977. “The Bass Part in Haydn's Early String Quartets.” The Musical Quarterly, v. 63, n. 3, p. 390-424.

53. Webster, James, and Georg Feder. 2001. "Haydn, (Franz) Joseph." Grove Music Online. Oxford University Press. 